\title{
LA APRECIACIÓN TÉCNICO CIENTÍFICA DEL PERITAJE PSICOLÓGICO EN LOS DELITOS CONTRA LA INTEGRIDAD Y FORMACIÓN SEXUALES DE LOS MENORES DE EDAD*
}

\author{
THE SCIENTIFIC AND TECHNICAL \\ APPRECIATION OF PSYCHOLOGICAL EXPERTISE \\ IN CRIMES AGAINST THE INTEGRITY AND \\ SEXUAL TRAINING OF MINORS
}

Juan José Cantillo Pushaina*

\begin{abstract}
Resumen
El trabajo rastrea la información existente sobre la apreciación técnico-científica del peritaje psicológico en materia de delitos contra la integridad y la formación sexuales de los menores de edad, con el fin de elaborar y dar a conocer el estado del arte correspondiente. Para ello, toma en cuenta los criterios de valoración probatoria regulados en el Código de Procedimiento Penal (CPP), en cual cada medio de prueba se describe de forma puntual y se hace especial referencia a la prueba pericial (art. 420 CPP). Estas pautas son de obligatorio seguimiento por parte del juez cuando evalúa las pruebas, sin que ello signifique una tarifa legal; por ello, se describen y analizan cada una de estas directrices, a saber: la idoneidad técnico-científica y moral del perito; la claridad y exactitud de sus respuestas; su comportamiento al responder; el grado de aceptación de los principios científicos, técnicos o artísticos en que se apoye el perito; los instrumentos utilizados; y la consistencia del conjunto de respuestas.
\end{abstract}

\footnotetext{
* Artículo de reflexión resultado del trabajo de grado para optar al título de Magíster en Derecho, Universidad Sergio Arboleda, Bogotá (Colombia). Agradecimientos al Dr. Marc David Schlagenhoff de la Ruprecht-Karls-Universitat Heidelberg, quien apoyó con las traducciones inglés-españolinglés.

** Abogado de la Universidad del Norte de Barranquilla, Especialista en Derecho Constitucional de la Universidad Libre; Magíster en Derechos Humanos, Estado de Derecho y Democracia en Iberoamérica de la Universidad de Alcalá de España y Magíster en Derecho de la Universidad Sergio Arboleda, Línea de Investigación en Derecho Procesal Penal. Abogado asesor del Grupo de Actividad Legislativa del Departamento Administrativo para la Prosperidad Social de la Presidencia de la República, es Miembro Internacional de la Asociación Latinoamericana de Psicología Jurídica y Forense, ALPJF.
} 


\title{
Palabras claves
}

Apreciación técnico-científica, caso Daubert, peritaje psicológico, prueba científica, prueba pericial, reglas de admisibilidad, reglas de valoración, valoración probatoria.

\begin{abstract}
The work traces the existing information on the technical-scientific appreciation of the psychological expertise in crimes against the integrity and sexual formation of minors, in order to elaborate and announce the condition of the corresponding art. To do this, it takes into account the criteria of probative assessment regulated in the Code of Criminal Procedure (CPP), where each means of evidence is described in detail and makes special reference to expert evidence (article $420 \mathrm{CPP}$ ). These guidelines are mandatory monitoring by the judge when evaluating the evidence, without this means a legal fee; For this reason, each of these guidelines is described and analyzed, namely: the technical-scientific and moral suitability of the expert; the clarity and accuracy of their responses; their response behavior; the degree of acceptance of the scientific, technical or artistic principles on which the expert is based; the instruments used; and the consistency of the set of answers.
\end{abstract}

\section{Keywords}

Admissibility rules, Daubert case, evidence assessment, expert evidence, psychological expertise, scientific evidence, technical-scientific assessment, valuation rules.

\section{Introducción}

La psicología es una de las ciencias que puede intervenir de modo crucial en los escenarios judiciales a través de los peritajes. Como disciplina que estudia el comportamiento humano para describirlo, explicarlo, predecirlo y controlarlo, se constituye en un valioso instrumento en el campo jurídico, a través de la llamada psicología jurídica, una sub especie de la psicología que estudia los comportamientos que pueden ser contemplados desde la perspectiva y las consecuencias jurídicas (Tapias \& Hernández, 2011).

En este sentido, es un importante apoyo para los jueces al momento de analizar y tomar sus decisiones en los procesos penales a su cargo, a través de los llamados peritajes psicológicos y ello con total independencia de que su ofrecimiento para respaldar una determinada teoría, se haga por parte de la fiscalía o de la defensa. Por esta razón, hoy es una realidad que el psicólogo jurídico intervenga cada vez más como perito en los procesos judiciales de abusos sexuales contra los menores de edad, en especial, para determinar su credibilidad cuando estos se declaran víctimas de algún tipo de abuso sexual. Estos peritajes psicológicos deben valorarse con base en los criterios técnico-científicos consagrados en el artículo 420 de la Ley 906 de 2004.

En este contexto, este trabajo tiene por objeto describir el estado del arte en punto de la apreciación técnico científica del peritaje psicológico en delitos sexuales contra los menores de edad desde el punto de vista jurídico penal probatorio, es decir, según los criterios consagrados en el artículo 420 CPP. Se busca, por ende, ofrecer un panorama legal, jurisprudencial y doctrinal que permita reconocer sus 
fundamentos y características esenciales, al igual que entender su importancia en nuestro medio, mejorar la comprensión de las normas colombianas correspondientes y hacer más eficaz su aplicación.

El problema se plantea desde dos preguntas básicas: ¿cuáles son los requisitos o criterios técnico-científicos para apreciar los peritajes psicológicos en casos de delitos sexuales contra menores de edad en el proceso penal colombiano?, y ¿cuál es el panorama del peritaje psicológico en casos de delitos sexuales contra menores de edad en Colombia, a la luz de los requisitos de cientificidad consagrados en el artículo $420 \mathrm{CPP}$ ?

Dar respuesta a estos interrogantes se justifica, por un lado, a partir de la escasa producción bibliográfica local sobre la materia y, por el otro, en atención a la relevancia que en el ámbito judicial han adquirido los delitos que atentan contra la libertad, integridad y formación sexuales de niños y niñas. A lo anterior, se suma otro asunto importante, pues, a la luz de la máxima judex est peritus peritorum (el juez es perito de peritos), cabe reflexionar en torno al poder suasorio que el juez les imprime a los dictámenes periciales. En general, lo expuesto muestra la relevancia de este estudio, pues surgen importantes inquietudes: ¿analizan los jueces penales de manera teórica y práctica los requisitos de la prueba científica o pericial, en nuestro caso, la psicológica? ¿Examinan los principios científicos, instrumentos y metodologías utilizados por el perito psicólogo? $\mathrm{O}$ ¿solo parten de la condición de 'perito psicólogo' para valorar su testimonio a partir de tal calidad? Al parecer, esto último es lo que ocurre en los procesos penales y ello afecta de manera grave el respeto de las garantías de los intervinientes, porque el peritaje psicológico se ha convertido en un elemento fundamental de conocimiento para proferir una sentencia a partir de meras valoraciones personales subjetivas y no científicas.

Si se parte de que la impunidad debe evitarse a toda costa, se entiende entonces que los derechos de nuestros niños, niñas y adolescentes son prevalentes y que dicho principio debe regir para el Estado, la familia y la sociedad; en consecuencia, se infiere que sus victimarios deben responder desde la perspectiva penal para restablecer, por lo menos de manera mínima (el daño es, en realidad, irreparable), los derechos de las víctimas. Pero dicho principio no puede ser aplicado en los procesos penales de manera dogmática; los peritajes psicológicos realizados al menor de edad deben cumplirse de manera científica y, por eso, el CPP establece unos criterios de valoración probatoria a los cuales está sometido el fallador (arts. 380 y 420 CPP).

Se hace necesario, por lo tanto, que el testimonio de un psicólogo presentado como perito (junto con el informe que le sirve de base según el art. 415 CPP) sea valorado de manera científica, con apego a los criterios que establece el art. 420 CPP. De esta manera, al emitir una sentencia de condena debe predominar la responsabilidad penal del procesado más allá de toda duda razonable, pues se corre el riesgo de que personas inocentes puedan ser condenadas por circunstancias distintas 
a la búsqueda de la justicia (venganza, intereses personales, no reconocimiento del error, una percepción equivocada de los hechos, una cacería de brujas, etc.).

Dicha garantía no es absoluta, pero minimizará el error judicial que se disfraza sobre la égida de los derechos de las víctimas y del interés superior del menor de edad, pues, es preciso reiterarlo, se deja sin posibilidades de una defensa real a quienes se les imputan delitos sexuales contra niños, niñas y adolescentes, convirtiéndose el proceso penal en una simple formalidad para condenar, lo cual le ocasiona a la sociedad un perjuicio debido a la apariencia de justicia que esconde. Tanto la práctica como la apreciación de pericias psicológicas deben hacerse con la consulta de los criterios técnicos científicos, porque ello redundará en beneficio de la sociedad y de las víctimas y obligará a que los peritos psicólogos sean profesionales idóneos para cumplir tal finalidad.

El objetivo general del estudio es elaborar el estado del arte de las principales normas, doctrinas y jurisprudencias penales que existen en torno a la apreciación técnico-científica del peritaje psicológico en materia de delitos sexuales contra menores de edad en Colombia. Para ello, se pretende cumplir con tres objetivos específicos: identificar los criterios técnicos científicos de valoración probatoria del peritaje psicológico a la luz del derecho procesal penal colombiano; referir algunos de los principales pronunciamientos jurisprudenciales de la Sala de Casación Penal de la Corte Suprema de Justicia sobre la materia; y plantear una propuesta legal en relación con el art. 420 CPP que estimule futuras exploraciones teóricas.

Por tratarse de una investigación exploratoria y documental, su metodología es descriptiva y analítica, pues sintetiza la esencia de los trabajos, monografías, artículos y pronunciamientos jurisprudenciales penales del derecho local sobre la cuestión escogida y las principales referencias internacionales sobre la prueba científica. Se analiza, al menos en forma tangencial, la pertinencia, naturaleza y profundidad de las aludidas fuentes. El trabajo se basa en la ubicación y recolección de información textual, presente en diferentes bibliotecas de la ciudad, en bibliotecas virtuales y páginas web de instituciones académicas reconocidas. Solo para efectos ilustrativos, se revisó el índice temático de consulta de jurisprudencia de la relatoría de la Sala de Casación Penal de la Corte Suprema de Justicia donde se hallaron en el descriptor "prueba pericial: apreciación", cuatro decisiones (radicados 28862 de 2008, 31795 de 2009, 32868 de 2010 y 39559 de 2013).

Desde el punto de vista doctrinario, se identificaron obras de autores que tratan sobre la prueba pericial psicológica, su importancia, finalidad y su valor en el proceso penal acusatorio colombiano. Sin embargo, es necesario reconocer que muy pocos desarrollan de manera específica la forma como debe valorarse dicho medio de prueba desde el punto de vista jurídico probatorio. Se reitera, son muy escasos los trabajos que se han escrito en materia de derecho penal procesal o de derecho probatorio sobre los criterios técnicos científicos que establece la Ley 906 de 2004, en especial, en el ámbito temático escogido en el presente trabajo. De ahí la necesidad y pertinencia de esta investigación. 
Por cuanto mira con la estructura del artículo, en primer término, se aborda la cientificidad de la prueba o prueba científica para establecer su equivalencia con la prueba pericial. Al respecto, se toma en cuenta la distinción de Gascón (2010) entre el control de admisibilidad procesal (pertinencia y legalidad) y el control de admisibilidad científica (validez científica) como controles previos al juicio oral de la prueba científica. Se advierte en este sentido que el primero hace parte del modelo europeo y el segundo del modelo angloestadounidense y se analiza por qué la Ley 906 de 2004 optó por el primero, para la audiencia preparatoria (fase intermedia). De forma sucinta se describen dos documentos de obligado conocimiento, relacionados con los criterios de valoración de la prueba pericial: el caso Daubert y el Reference Manual of Scientific Evidence del Federal Judicial Center (2011). Enseguida, se hace referencia a los antecedentes normativos en el ámbito procesal penal relacionados con los criterios de valoración probatoria, para terminar con el examen de la Ley 906 de 2004.

En un segundo momento, se continúa con la descripción doctrinaria y jurisprudencial de la apreciación técnico-científica de la prueba pericial en general (la ubicada en la relatoría de la Corte Suprema que se comentó antes), para desembocar en el tercer subtema de la prueba pericial psicológica en casos de delitos sexuales contra menores de edad. Para culminar, se concluye que la literatura sobre la apreciación técnico-científica del peritaje psicológico en delitos sexuales es casi nula y se formula una propuesta legal encaminada a que se produzca una reforma del artículo 420 CPP.

Todo lo anterior con la finalidad de desarrollar, profundizar y dar a conocer estudios en torno a los criterios de valoración probatoria, asimilables y aplicables en nuestro contexto. No de cada medio de prueba en general (testimonio, documento, peritaje, etc.), sino de cada uno en concreto que pueda servir de guía para casos semejantes; como podría ser el que se relaciona con la prueba científica, en nuestro caso, con la pericial psicológica en delitos sexuales contra los menores de edad y, dentro de esta, la que busca determinar la credibilidad del testimonio de menores de edad víctimas de abuso sexual.

\section{Reseña sobre la apreciación judicial de la prueba pericial o prueba científica}

\section{Consideraciones previas.}

Uno de los retos más relevantes del derecho probatorio moderno es la prueba científica (Taruffo, 2012, cuya autoridad académica es reconocida por especialistas en el tema de la valoración de la prueba científica en el proceso judicial: Ferrer, 2006; Ibáñez, 2009; Gozaíni, 2012; Iuris, 2012, entre otros); sin embargo, aunque existe un conocimiento mínimo sobre la materia, la fuente bibliográfica que más se aproxima a su desarrollo actual es el Reference Manual of Scientific Evidence del Federal Judicial Center, United States of America. La prueba científica, pues, ha adquirido hoy gran relevancia debido a que cada vez se utilizan peritajes con mayor frecuencia en los diversos procesos judiciales (Breyer, 2011; Taruffo, 2012); por ello, el uso de las mismas en el proceso contemporáneo, esto es, la motivación o 
fundamentación de la decisión del juez en conocimientos científicos, minimiza en gran medida la incertidumbre, la subjetividad y la arbitrariedad, para generar un aumento en el grado de certeza dada la posibilidad de verificación de la información que se ofrece con tales medios de prueba (Taruffo, 2009).

Sin embargo, algunos autores identifican la prueba científica con la prueba pericial (Devis, 1971; Verbic, 2008; Taruffo, 2012; Fernández, 2012; Lluch, 2012; Vázquez, 2013), entendiéndola como aquella que requiere el conocimiento de un experto "en la materia y la aplicación de un procedimiento reglado" (Fernández, 2012, p. 70) en aspectos tan especializados como pruebas de ADN, balística, peritaje psicológico, etc. No obstante, los métodos científicos no originan nuevos medios de prueba (tanto para su formación como para determinar su veracidad), sino que son una adecuada forma de averiguar o precisar la verdad (Denti, 1972).

Sin embargo, para otros expositores (Pabón, 2006; Falcón, 2012; y, Gozaíni, 2012) la prueba científica no es pericial; aquella es un medio de prueba independiente no legislado (Falcón, 2012; Gozaíni, 2012). A este respecto, adviértase que los modelos adoptados por los Estados pueden ser de dos clases: 1) un sistema de pruebas típicas, que es un modelo cerrado, en estos casos, el legislador establece de forma taxativa cuáles son los medios de prueba, de manera que los no consignados de forma expresa en la ley se consideran prohibidos por ese solo hecho; y, 2) un sistema de pruebas atípicas, esto es, un modelo abierto, en cuya virtud existe libertad para solicitar, presentar, admitir, practicar y valorar cualquier medio de prueba, se encuentre o no específicado por la ley, siempre que no viole derechos fundamentales o el ordenamiento jurídico. De los arts. 373 y 382 CPP se puede inferir que el legislador optó en el proceso penal por un sistema de pruebas atípicas, teniendo en cuenta que los medios de conocimiento que relaciona el Código son solo enunciativos.

Por supuesto, no es esta la oportunidad para discutir esta cuestión pero se debe precisar que la prueba pericial es un concepto general y la prueba científica uno específico. El primero, relacionado con cualquier conocimiento científico, técnico, artístico o especializado al que se refiere el art. 405 de la Ley 906 de 2004; mientras que, el segundo, se vincula solo y de manera exclusiva con el conocimiento científico (Ferreyra de la Rúa \& Bella, 2008). Así las cosas, para los efectos de este trabajo, se acoge la equivalencia entre prueba científica y prueba pericial.

Así las cosas, como se hace necesaria la aportación de los conocimientos técnico científicos por parte de un perito al proceso, el problema se centra en saber cuáles son los criterios que debe seguir el fallador para realizar una correcta apreciación de la prueba científica o la prueba pericial aportada. Aquí se debe distinguir entre los sistemas (derecho continental o civil law) que posibilitan al juez decretar de oficio el auxilio de peritos, de aquellos (common law) que dejan la aportación de la prueba pericial como una facultad exclusiva de las partes (Denti, 1972; Taruffo, 2005; Granados, 2005; Ramírez, 2006; Vázquez, 2013). Sin embargo, en los Estados Unidos de América, pese a no ser una práctica judicial muy usual, la Regla 
Federal de Evidencia 706 (2014) consagra la posibilidad de que los juzgadores designen expertos o peritos de manera oficiosa (Chiesa, 1995; Taruffo, 2003; Muñoz, 2006; Verbic, 2008). En el derecho positivo, el CPP vigente adoptó el sistema del common law y, en su artículo 361, establece que al juez de conocimiento le está vedado decretar la práctica de pruebas de oficio; sobre ello, la Corte Constitucional (Sentencia C-396 de 2007) señala que tal prohibición hace parte del sistema penal acusatorio adoptado por la Constitución, no obstante lo cual esta prohibición no es absoluta, por cuanto los jueces con funciones de control de garantías sí podrían decretar la práctica de pruebas de oficio para la toma de decisiones relacionadas con la materia objeto de control.

Ahora, respecto al control de la prueba científica, la Ley 906 de 2004 optó por el modelo europeo o civil law (Fernández, 2012 y Lluch, 2012), cuyo control se desarrolla en la etapa de valoración de la prueba, pues, de forma previa, solo está sometida a simples razones de pertinencia; ello al contrario de lo ocurrido en el modelo angloestadounidense, en el cual existe un control de admisibilidad anterior al juicio oral y en el que se determina la validez científica de la prueba. El primero, se denomina como control de admisibilidad procesal de la prueba (pertinencia y legalidad), mientras que el segundo se comoce como un control de admisibilidad científica de la prueba (validez científica) (Gascón (2010); por ello, en el modelo europeo, todas las pruebas científicas pertinentes y legales deben ser admitidas, remitiendo la cuestión de la validez científica al momento de la valoración probatoria, es decir, no se evalúa en el trámite de admisibilidad de la prueba y se confunde con la fuerza probatoria de la misma (Gascón, 2010).

La admisibilidad en sentido estricto, debe ser definida como la aceptación por parte del juez del medio de convicción que se presenta por las partes y en el que se califica con antelación su legalidad y pertinencia, sin que ello signifique una valoración de su fuerza probatoria (Devis, 2010). En el sistema penal acusatorio vigente, tanto la defensa como la fiscalía tienen el deber de fundamentar -en la audiencia preparatoria- la admisibilidad de los elementos materiales probatorios o testimonios que pretenden llevar al juicio oral. Si bien, el escenario procesal penal por excelencia para realizar el análisis de admisibilidad por el juez es la audiencia preparatoria (arts. 357 y $359 \mathrm{CPP}$ ), también es cierto que, de acuerdo con la jurisprudencia penal, el decreto de los medios de prueba en esta audiencia no impide que el juez en el juicio verifique que su práctica se ciña a los motivos que fundamentaron su admisión.

A este respecto, la jurisprudencia señala que, al ubicarse las disposiciones atinentes a la pertinencia y la admisibilidad de los medios de prueba en el Capítulo III del Título IV CPP -relativo a la práctica de la prueba en el juicio-, este es el momento en el que, de verdad, se hace evidente lo concerniente a la admisibilidad de las pruebas por cuanto ellas se decretan en la audiencia preparatoria sin que se conozca con certeza su contenido, "sino basándose únicamente en la justificación que ofrezca la parte interesada en la respectiva solicitud probatoria". Por esta razón, el juez: 
queda facultado para que durante su práctica en el juicio, pueda verificar que la misma cumple el presupuesto de pertinencia, para lo cual habrá de confrontar lo que la prueba muestra con los hechos o circunstancias que se busca demostrar, y también con las razones esgrimidas cuando se pidió su admisión. (Corte Suprema de Justicia, Auto 36784, 2012).

Ahora bien, el art. 376 CPP consagra las condiciones generales de admisibilidad probatoria al señalar que toda prueba pertinente es admisible, salvo que: (a) exista peligro de causar grave perjuicio indebido, (b) tenga una probabilidad de generar confusión en lugar de mayor claridad al asunto o exhiba escaso valor probatorio, y, (c) sea dilatoria del procedimiento de forma injusta; por lo tanto, el medio de prueba que no es pertinente no es admisible (Defensoría del Pueblo, T. I., s.f.). Por otra parte, la admisibilidad específica de cada medio probatorio depende de sus normas particulares, pues el art. $376 \mathrm{CPP}$ es la norma general que condiciona su ingreso al proceso a partir de la legalidad y la pertinencia de la misma y, por consiguiente, establece el control general de admisibilidad en un momento previo al juicio oral (Defensoría del Pueblo, T. I., s.f.); el modelo adoptado aquí, puede decirse, es un control general de admisibilidad procesal.

Sobre ello, debe señalarse que revisadas las Actas de la Comisión Redactora del texto que introdujo el llamado Sistema Penal Acusatorio SPA, se encontró que no fue discutido el tema de la admisibilidad en la audiencia preparatoria de la prueba de manera general o de forma especial de la prueba pericial. Tampoco, se trató la cuestión de la validez científica de la prueba pericial, menos como control de admisibilidad científica previo al juicio oral en aplicación de los criterios de cientificidad fijados en el caso Daubert. Lo que sí se mencionó, de forma muy breve, al discutirse sobre la Casación en el Acta 31, fue la importancia de unificar la jurisprudencia y el tema de admisibilidad en el entendido sobre qué prueba se puede ver o no en juicio (Granados, 2005). Sin embargo, tal y como quedó el texto de la Ley 906 de 2004, y se evidencia en la praxis jurídica, se colige sin mayor dificultad la adopción del modelo europeo en materia de control de admisibilidad de la prueba científica en los términos expuestos en el presente trabajo.

Ahora bien, el control especial de admisibilidad de la prueba científica o pericial previo al juicio oral, esto es, en la audiencia preparatoria, que sigue siendo solo procesal como se demostrará en seguida, se puede abordar desde dos puntos de vista: el normativo (el deber ser o lo que dice la norma procesal penal) y el descriptivo (lo que es o lo que sucede usualmente en la práctica judicial).

Una interpretación exegética de los arts. 412, 413 y 414 CPP nos indica las 'condiciones especiales de admisibilidad procesal' que deben verificarse en la audiencia preparatoria y se refieren a la presentación de informes de peritos por las partes (no se verifica su validez científica, sino la existencia del informe) y la certificación que acredite la idoneidad de los peritos. De acuerdo con el Código, de admitirse el informe por parte del juez en la audiencia preparatoria, se citará al perito que lo 
suscribió para que concurra al juicio oral con el fin de ser interrogado y contrainterrogado.

Ahora bien, muchos jueces aplican la interpretación anterior al realizar el estudio de admisibilidad de las pruebas periciales, con la curiosidad de que la exigencia de la certificación que acredita la idoneidad del perito no le es impuesta a la fiscalía bajo el argumento de que dada su calidad de servidores públicos debe presumirse la legalidad de sus actos (Jiménez et al., 2009; 2012)). No obstante, aunque la Ley 906 de 2004 no lo requiere así de manera clara (arts. 413 y 408), es conveniente que al realizar la petición de la prueba pericial en la audiencia preparatoria se acredite la idoneidad del perito por medio de la presentación de la hoja de vida con sus anexos, para evitar "que una malintencionada oposición o una desafortunada interpretación judicial ocasionen el rechazo de la solicitud probatoria" (Albarracín, 2009, p. 57). Así mismo, de ser posible también debe acompañarse el informe pericial que se pretende incorporar en el juicio a través del testimonio del perito.

No obstante, la conclusión descrita es equivocada (Jiménez, 2012; Albarracín, 2009), puesto que, interpretados sistemáticamente los arts. 412, 413 y 414 CPP en armonía con los arts. 408 y 417 ibídem, la certificación de idoneidad no es una condición de admisibilidad, porque para ello se puede utilizar cualquier medio de prueba admisible, incluida la propia declaración de la persona que se presenta como perito, la cual puede acreditarse en la misma audiencia del juicio oral. No obstante, la eventualidad descrita no es una situación frecuente en la práctica judicial en el sistema penal acusatorio colombiano (Jiménez, 2012), porque son casos excepcionales los casos de inadmisión, con la aclaración de que estos se refieren a aquellos informes periciales que no fueron obtenidos en la etapa de investigación o lo fueron de manera posterior a la audiencia preparatoria. Lo que casi siempre se presenta en los procesos penales es que la idoneidad del perito se verifique en el juicio oral.

Para sustentar lo expuesto y con el fin de aproximar estas reflexiones al contexto judicial, una encuesta realizada de manera aleatoria a defensores públicos y de confianza -'privados'-, muestra cual es la situación real. No obstante, para una valoración real del asunto resulta importante tener presente, en primer lugar, que según un estudio realizado por la Universidad Javeriana, a 2010, la carga anual de los defensores públicos era de 161 procesos en el sistema penal acusatorio, mientras que la de los defensores privados era solo de 5 (Hernández, 2010) y, a tono con la Corporación Excelencia en la Justicia CEJ (2010), a 2008, los defensores públicos en el sistema penal acusatorio atendieron un total de de 72.786 procesos.

En segundo lugar, la población encuestada estuvo integrada por abogados adscritos a once defensorías regionales (Bogotá, Guajira, Boyacá, Antioquia, Amazonas, Cauca, Valle del Cauca, Guaviare, Guainía, Magdalena Medio y Meta) incluida la de Bogotá, en cuya regional la encuesta se realizó a través de cuatro profesionales administrativos y de gestión (coordinadores), un coordinador académico y un asesor de la unidad operativa de investigación criminal de la Dirección 
Nacional de Defensoría Pública- de las 36 existentes en la Defensoría del Pueblo encargadas de prestar el servicio de defensoría pública en el sistema penal acusatorio y cuatro - de los doce- defensores públicos de la Oficina Especial de Apoyo de la Dirección Nacional de Defensoría Pública, en todo el país. Asimismo, por el lado de los defensores privados, se entrevistó a abogados pertenecientes a una firma.

La encuesta constaba de dos preguntas: 1) ¿Tiene usted conocimiento de algún caso en el sistema penal acusatorio colombiano, en el cual en la audiencia preparatoria el juez de conocimiento haya inadmitido una solicitud de prueba pericial porque la parte solicitante no aportó la certificación que acreditara la idoneidad del perito? 2) ¿O porque la parte solicitante no acompañó a la solicitud en la audiencia preparatoria el correspondiente informe pericial? La mayoría de las respuestas fue negativa. Sin embargo, se halló un caso conocido por la defensoría pública en Bogotá, D. C., en el cual la respuesta a la primera pregunta fue positiva y tuvo lugar en un proceso por el delito de acto sexual abusivo con menor de 14 años, seguido ante el Juzgado 7 Penal del Circuito; la decisión fue apelada por la defensa y la decisión fue confirmada por la Sala Penal del Tribunal Superior del Distrito Judicial de Bogotá.

Así las cosas, de la encuesta realizada y sus resultados (un solo caso hallado de inadmisión en la audiencia preparatoria por ausencia de la certificación de idoneidad), se puede concluir que la interpretación descrita antes acontece de forma muy excepcional. Incluso, en la práctica judicial, se evidencia que la fiscalía anuncia con alguna frecuencia en el escrito de acusación y, luego, en la audiencia de formulación de acusación, un informe pericial que será presentado con posterioridad, pero el mismo tampoco es entregado muchas veces en la audiencia preparatoria (Martínez, 2013; González, 2014; Rivera, 2014).

También, acontece que la fiscalía anuncia el informe pericial en la audiencia de formulación de acusación -y luego en la audiencia preparatoria- con el fin de entregarlo al menos con cinco (5) días de anticipación a la celebración de la audiencia pública del juicio en donde se practicará la peritación, sin perjuicio del correspondiente decubrimiento (Martínez, 2013; González, 2014; Rivera, 2014). Este descubrimiento se cumple, de acuerdo con la Sala de Casación Penal de la Corte Suprema de Justicia (Sentencia 25920 de 2007), con el acatamiento del deber funcional de la fiscalía de anunciar desde el escrito de acusación las pruebas que hará valer en el juicio oral o informando a la defensa las que va a utilizar para sustentar la acusación. En este caso, la realización futura y entrega de un informe pericial y su correspondiente incorporación a través del respectivo perito puede hacerse, incluso, desconociéndose cuál es el perito que de manera particular elaborará dicho informe en la audiencia preparatoria y, por consiguiente, es imposible verificar la idoneidad de un perito que en ese momento procesal no se conoce.

Lo anterior, también aplica para la defensa, tal y como ocurre en la práctica judicial. Inclusive, se conoce de casos en los que la defensoría pública solicita pruebas periciales en la audiencia preparatoria previo informe en el sentido de que existe 
una solicitud para designar un perito ante la Unidad Operativa de Investigación Criminal de la Defensoría Pública UOIC y, por ende, después de argumentar solo razones de pertinencia de la prueba pericial y comprometiéndose a suministrar con posterioridad el informe pericial y los datos del perito -en todo caso, antes de los cinco días a su práctica en el juicio oral- (González, 2014 y Rivera, 2014). No obstante, téngase en cuenta que el artículo 415 CPP consagra que en ningún caso el informe será admisible como evidencia si el perito no declara en el juicio oral, con lo cual, concluye Bedoya (2008), si el perito declara en el juicio el mismo sí sería admisible como evidencia para que el juez tenga un mejor conocimiento del caso al momento de la correspondiente valoración probatoria.

Además, para la Sala de Casación Penal de la Corte Suprema de Justicia (Sentencia 25920 de 2007), la base de la opinión pericial, que es el informe pericial, cuando se obtiene en la fase investigativa, "se sujeta a las reglas de descubrimiento y admisión en la audiencia preparatoria" (art. 414 CPP) o "se rinda en audiencia pública, cuando así lo solicita la parte interesada” (art. 412 CPP). De manera que, si la obtención del informe del perito es posterior a la audiencia preparatoria, es viable el empleo de dicha evidencia siempre que se descubra con cinco días de anticipación a la celebración de la audiencia pública donde se practicará la peritación (Bedoya, 2008; Fiscalía, 2009). Así mismo, para la Fiscalía General de la Nación (2009, pp. 153-154), “(la prueba) pericial está regulada por el principio de pertinencia en cuanto a la admisibilidad se refiere", pues "los principios en que se fundamentó el perito; las reglas de procedimiento que siguió; el método que utilizó; su grado de confiabilidad; los instrumentos que usó; [esto es, su validez científica], son aspectos de singular importancia, [sobre los cuales] se ocuparán las partes de interrogarlo en el juicio oral para verificar su conocimiento e idoneidad", mientras el juez lo hará al momento de la valoración.

Lo ideal, pues, es que en la audiencia preparatoria se genere un espacio ex ante en el que se discuta sobre la idoneidad del perito que va a declarar en el juicio oral, para evitar que en él declaren personas que no poseen la experiencia o preparación en el área científica, técnica o especializada respectiva; obvio es decirlo, lo anterior también puede discutirse en sede de juicio oral (Albarracín, 2009). Esto último, es lo que ocurre por regla general en los actuales procesos penales. Al respecto, recuérdese que en el sistema estadounidense varias de sus reglas probatorias y el análisis teórico correspondiente giran en torno a qué pruebas se presentarán al jurado y, por esta razón, los controles de admisión son más relevantes en su régimen de prueba que en el sistema europeo o civil law (Vázquez, 2013). Por ello, al disponer el control de admisibilidad de la prueba científica antes de su práctica o previo al juicio en el sistema penal acusatorio colombiano, se hace referencia de forma exclusiva al control realizado en la etapa intermedia de preparación del juicio, esto es, la audiencia preparatoria (la puerta de entrada de los medios de prueba al proceso para hacerlos valer en el juicio oral), el cual difiere del control de admisibilidad de la prueba pericial en el juicio oral o durante su práctica en lo que a la oportunidad procesal se refiere. Tal vez por ello, para la Sala de Casación Penal de la Corte Suprema de Justicia (Auto 36784 de 2012), el juez está facultado para que, 
durante su práctica en el juicio oral, verifique si se cumple con el presupuesto de la pertinencia teniendo en cuenta las razones que fundamentaron su admisión. En todo caso, el control previo que se realiza en Colombia es procesal y no científico.

Por último, la presentación del informe pericial para ser incorporado como evidencia a través del perito durante su declaración en el juicio oral, se relaciona con las reglas de incorporación de los elementos materiales de prueba y evidencia física, documental y pericial para que sean tenidos en cuenta como pruebas dentro del juicio oral y en donde el juez decide sobre su admisibilidad. Recuérdese que la prueba científica o pericial está conformada por dos actos: uno, el informe del perito (base de la opinión experta) y, otro, el testimonio personal de este último dentro del juicio oral (Sala de Casación Penal de la Corte Suprema de Justicia, sentencias 29609 de 2008 y 31795 de 2009); además, téngase en cuenta que no existe una normatividad sobre el método de incorporación y autenticación de las evidencias en el juicio oral. No obstante, se puede acudir a los principios generales de la prueba y a la legislación comparada para incorporar en el juicio oral la evidencia y que pueda ser valorada por el juez, siguiendo las siguientes etapas: "establecer las bases probatorias para la incorporación"; "marcar como identificación y pedir permiso al juez para su exhibición al testigo"; "mostrar la identificación a la otra parte"; "establecer las bases probatorias para la autenticación y autenticar"; "ofrecer como medio de prueba [o evidencia] autenticada" y "admitir como medio de prueba o [evidencia]" (Reyes \& Said, 2009).

En el apartado siguiente se describe lo que ocurre en el sistema estadounidense a propósito del control de admisibilidad de la prueba científica (validez científica) anterior al juicio oral en aplicación de los requisitos del caso Daubert. Al hilo de ello, se propone reflexionar sobre el control de admisibilidad previo al juicio oral que se hace en Colombia.

\section{Dos necesarias referencias internacionales.}

Antes de conocer cuáles son los criterios para la correcta valoración de la prueba en el proceso penal colombiano, en especial, de la pericial y, sobre todo, en los casos de delitos contra la integridad y formación sexual de los menores de edad, se hace necesario revisar dos pautas que, según Taruffo (2012), son el caso Daubert de la Suprema Corte de los Estados Unidos y el Reference Manual of Scientific Evidence (Federal Judicial Center, 2013).

\section{El Caso Daubert.}

En esta decisión se trató de manera concreta sobre la admisibilidad de la prueba novel científica en el juicio oral; la discusión giró en torno a la continuidad de la regla de aceptación general establecida en el caso Frye en 1923 y de su inaplicabilidad, en razón de la adopción de las Reglas Federales de Evidencia de 1975. La prueba de Frye tiene su origen en la admisibilidad de la prueba de engaño de presión sistólica de la sangre, un cruel predecesor de la máquina del polígrafo; como la misma no se encontraba acreditada en debida forma, esto es, no contaba con la 
aceptación general en el campo particular al que pertenecía, ella fue declarada inadmisible (Federal Judicial Center. National Research Council, 2011).

Al respecto, recuérdese que los padres de los niños Jason Daubert y Eric Schuller demandaron a Merrell Dow Pharmaceutical, porque los menores nacieron con graves defectos congénitos, debido a la ingestión por parte de las madres de Bendectin, un medicamento que se les recetó contra las náuseas, comercializado por el demandado. Este alegó que el producto Bendectin no causaba malformaciones congénitas en los seres humanos y que los demandantes no podían presentar cualquier prueba para demostrar su teoría. Para apoyar su defensa, el demandado presentó una declaración jurada de Steven H. Lamm, médico y epidemiólogo, experto acreditado sobre los riesgos a la exposición a diversas sustancias químicas. El Dr. Lamm declaró que había revisado la literatura científica existente sobre el Bendectin y concluyó que esta no era una sustancia capaz de provocar malformaciones en los fetos. Los demandantes, a su vez, no impugnaron los estudios publicados sobre Bendectin y, en su lugar, respondieron a la defensa del demandado con el testimonio de otros ocho expertos, cada uno de los cuales también poseían impresionantes credenciales. Estos últimos concluyeron que el Bendectin podía causar defectos de nacimiento; sus conclusiones fueron producto de diversos estudios en animales sobre la base in vitro (tubo de ensayo) e in vivo (en seres vivos) en los que se encontró un vínculo entre el Bendectin y las malformaciones. Es más, se realizaron estudios farmacológicos sobre la estructura química del Bendectin que pretendían mostrar similitudes entre la estructura de la droga y de otras sustancias que causaban defectos de nacimiento, así como el nuevo análisis de los estudios epidemiológicos publicados anteriormente (Federal Judicial Center. National Research Council, 2011).

De acuerdo con el estándar Frye, que era el predominante y aceptado por la mayoría de los tribunales estadounidenses, la opinión de expertos era inadmisible a menos que la teoría o técnica fuese aceptada de manera general por la comunidad científica a la que pertenece. Así las cosas, la Corte Suprema de Justicia de los Estados Unidos resolvió el problema con base en la aplicación e interpretación de las normas federales y, de manera concreta, la Regla 702 que rige el testimonio de expertos, para afirmar que nada dice el texto normativo sobre la aceptación general como condición sine qua non para la admisibilidad, por lo cual concluyó que la doctrina Frye era incompatible con las Reglas Federales de Evidencia y, por tal razón, decidió que no debía aplicarse.

Asimismo, la Corte Suprema de Justicia de los Estados Unidos (1993), con base en las Reglas Federales de Evidencia 104 (a) 10, 402, 401, 701, 703 y, en especial, la 702, ha fijado de manera general los seis criterios de admisibilidad para que un experto o científico rinda testimonio en el juicio oral: en primer lugar, la prueba debe ser relevante. Ello se traduce en la pertinencia y significa que debe referirse a los hechos en cuestión o a sus consecuencias, al igual que a su determinación más o menos probable. De este modo, debe ayudar al juez a comprender la evidencia o a determinar un hecho en discusión y, además, debe fijar una conexión científica 
con los hechos objeto del proceso. La pertinencia es, por lo tanto, una condición para la admisibilidad.

En segundo lugar, la prueba debe ser fiable, pues la fiabilidad se obtiene de un procedimiento adecuado y con resultados lógicamente obtenidos, en donde se examina la coherencia del informe (metodología, resultados y conclusiones); el objeto del testimonio experto (peritaje) ha de ser un conocimiento científico que ayude al juez a comprender la evidencia o a determinar un hecho en cuestión (Verde, 2005). El término 'científico' se relaciona con los métodos y procedimientos que la ciencia utilice, por ello, deben ser conocidos con suficiencia para que se establezca un estándar de prueba confiable basado en el conocimiento y la experiencia del experto en una disciplina.

En tercer lugar, la teoría o técnica científica en la que se basa la prueba ha de ser verificada o probada para determinar si puede ser falsificada, así, el estatus científico de una teoría o técnica es su falsabilidad o refutabilidad o su capacidad de prueba; la irrefutabilidad no es una virtud, sino un vicio (no puede ser científica), por lo cual la refutabilidad (intento por desmentir o refutar una teoría) es el criterio que establece el estatus científico de una técnica o teoría (Popper, 1980, p. 39). La metodología es válida desde el punto de vista científico y adecuada para aplicarla a los hechos que se pretenden entender o determinar.

En cuarto lugar, la teoría o técnica en la que se basa la prueba es la verificación sobre si ha sido sometida a revisión por sus pares o ha sido objeto de publicación, pero la publicación no es un requisito sine qua non para la admisibilidad de la prueba, dado que no se relaciona con su fiabilidad; en consecuencia, será importante, aunque no decisiva. En quinto lugar, debe considerarse el conocido o potencial margen de error de la técnica científica utilizada. Y, en sexto lugar, la aceptación general de la comunidad científica de los principios y la metodología en que se apoya la prueba pericial es primordial; no obstante, la aceptación general no es un requisito necesario para la admisión de los testimonios de expertos.

La evaluación de la admisibilidad del testimonio experto recae solo sobre los principios y la metodología de la ciencia, no sobre las conclusiones que genera; empero, esta prueba puede ser excluida si causa un perjuicio injusto, induce en error al jurado o genera confusión (Regla 403, similar al art. 376 de la Ley 906 de 2004), porque estos criterios son solo estándares o condiciones de cientificidad (Taruffo, 2005 y 2006). El juez no puede asumir una posición pasiva frente a la prueba científica que se le presente sino que, en su papel de gatekeeper, debe proceder a verificar la validez y atendibilidad de la misma, de tal forma que pueda comprobar la admisibilidad de su declaración como experto para el juicio oral; su objetivo es, pues, el de dejar por fuera de la esfera de las desiciones judiciales a la pseudociencia (Taruffo, 2005).

Como ya se dijo, se denomina 'control de admisibilidad científica' la verificación de la validez científica de la prueba hecha por el juez, de manera previa al juicio oral y en aplicación de los requisitos del caso Daubert; mientras que, acorde 
con el modelo europeo sobre el particular, la validez de la prueba científica se hace a propósito de la valoración de la prueba, de allí que se hace necesario esclarecer "la distinción entre validez o fiabilidad científica de la prueba y su valor probatorio" (Gascón, 2010).

La primera está condicionada por el control previo "de sus postulados ajustado a una metodología científica", esto es, "no es algo que haya que dar por descontado, sino que depende de la validez científica del método usado, de que se haya utlizado la tecnología apropiada y de que se hayan seguido rigurosos controles de calidad" (Gascón, 2010, p. 90). La segunda, por su parte, consiste en que el juez atribuye a las conclusiones del informe pericial -y de la declaración del perito- "un peso en la formación de su convicción sobre las hipótesis de las partes" (Gascón, 2010, p. 101). Por está razón, el test Daubert no incluye la evaluación de las conclusiones de la prueba científica, porque esta sí se realiza en la etapa de valoración probatoria; el caso Daubert establece criterios de admisibilidad y no de valoración de la prueba científica, que se aplican a toda clase de pruebas periciales inadmiténdose las poco fiables (Ramírez, 2006; Allen, 2012). Ahora bien, con independencia del modelo por el que se opte, "la admisibilidad de las pruebas depende mucho de si se da o no por descontada su fundamentación científica" (Gascón, 2010, p. 94).

Como se mencionó en el capítulo anterior, la Ley 906 de 2004 optó por el modelo europeo o de civil law (Fernández, 2012; Lluch, 2012) y el control admisibilidad previo al juicio oral, esto es, el realizado en la audiencia preparatoria, es de carácter procesal y no científico, pues no se verifica la validez científica del informe pericial que se enuncia y presenta como evidencia y que será incorporada al juicio oral a través de la correspondiente declaración del perito. En principio, la audiencia preparatoria es la oportunidad en que se constata la pertinencia de la prueba pericial y la presentación del informe del perito por la parte interesada, si este se obtuvo en la fase investigativa, sin que haya lugar a cuestionamientos distintos a las mismas razones de pertinencia.

Así lo expresa la jurisprudencia de manera general, por cuanto las pruebas se decretan en la audiencia preparatoria sin que se conozca con certeza lo que será su contenido, "sino basándose únicamente en la justificación que ofrezca la parte interesada en la respectiva solicitud probatoria" (Corte Suprema de Justicia, Auto 36784, 2012). Por ello, el caso Daubert "es un mínimo tratado de epistemología" (Taruffo, 2014) y, a partir de él, la tendencia en los actuales procesos judiciales es hacer menos referencia a las máximas de la experiencia, el sentido común y la cultura media y, con más frecuencia, aludir a la ciencia como tipo de conocimiento para resolver problemas que desbordan la cultura del hombre común.

\section{El Manual de referencia sobre evidencia científica.}

Este texto o Reference Manual on Scientific Evidence es fruto de las elaboraciones llevadas a cargo por el Federal Judicial Center (2011) que, con toda razón, es calificado como un material único sobre pruebas científica (Taruffo, 2012). Desde luego, no cabe duda en el sentido de que, en materia de la admisibilidad del testimonio 
de expertos, la trilogía Daubert (casos Daubert $v$. Merrell Dow Pharmaceuticals; General Electric $v$. Joiner; Kumho Tire $v$. Carmichael; y Weisgram $v$. Marley) cambió de forma drástica el testimonio de testigos expertos en los procesos judiciales, pese a que el interés de la Corte era fijar unos criterios que sirvieran de guía a los jueces de primera instancia para la admisiblidad de las pruebas periciales, no obstante su generalidad fue una circunstancia que propició muchas críticas y conflictos inclusive entre las Reglas Federales de Evidencias y las propias directrices Daubert (Berger, 2011). Por eso, el susodicho Manual, dirigido a los jueces para facilitar su entendimiento de la ciencia y sus aspectos éticos, así como para que los diferentes peritos o científicos conozcan la práctica legal y del testimonio judicial, es, en los Estados Unidos, un esfuerzo científico-jurídico en orden a promover el interés en la busqueda de la verdad y la justicia (Breyer, 2011).

\section{Antecedentes de los criterios de apreciación de la prueba penal en Colombia.}

Los criterios de valoración de la prueba no son una primicia traída por el sistema penal acusatorio actual; los Decretos 1345 de 1970 y 409 de 1971 ya otorgaban valor probatorio a determinados medios de prueba bajo las figuras jurídicas de prueba plena y prueba incompleta: el Decreto 1345 de 1970 establecía el valor probatorio para el acta de inspección (art. 222), para un solo indicio (art. 224), para el testimonio (art. 213), el documento público (art. 256), el documento privado (art. 257), el reconocimiento de documentos (art. 258), la confesión (art. 260) y el dictamen del perito (art. 274); en este último caso, la norma establecía que el dictamen del perito por sí solo no era plena prueba. Salvo por lo atinente al reconocimiento de documentos, el Decreto 409 de 1971 repitió la fórmula en los mismos medios de prueba (arts. 228, 230, 236, 261, 262, 264 y 278).

El Decreto 50 de 1987 consagró la regla general para la apreciación de la prueba en el art. 253 y estableció que los medios de prueba debían valorarse en su conjunto de acuerdo con las reglas de la sana crítica. De modo especial, reguló la apreciación del testimonio (art. 295) y, por primera vez, utilizó con la confesión la expresión "criterios para apreciar" (art. 300). Asimismo, el Decreto 2700 de 1991 y la Ley 600 de 2000 incluyeron unos criterios de apreciación. En la primera normatividad, dichos criterios (art. 254) se establecieron de forma específica para el dictamen (art. 257), el testimonio (art. 294), la confesión (art. 298) y los indicios (art. 303). En la Ley 600 de 2000, la regla general sobre la apreciación de los medios de prueba se encuentra en su art. 238 y, de manera especial, se consagraron para el dictamen (art. 257), el testimonio (art. 277), la confesión (art. 282) y los indicios (art. 287).

\section{Los criterios para apreciar la prueba regulados en la Ley 906 de 2004.}

El art. 380 de la Ley 906 de 2004 establece los criterios de valoración probatoria y remite a las normas que los desarrollan a propósito de cada medio de prueba; también, se regulan, de forma especial, los criterios de apreciación técnico científicos de las pruebas testimonial (art. 404), pericial (art. 420), documental (art. 432) y de referencia (art. 441). Sin embargo, la doctrina si bien no habla de manera expresa sobre la apreciación técnico científica de las pruebas penales, incluye dichos 
criterios dentro del método de las reglas de la sana crítica para valorar las pruebas, al fundamentar normativamente la adopción de la sana crítica como método de valoración probatoria en el sistema penal acusatorio con base en los arts. 404, 420, 432 y $441 \mathrm{CPP}$, que contienen los criterios técnico-científicos para valorar cada uno de los medios de prueba consagrados en dicha normatividad (Parra, 2011).

Tal vez por ello, dentro de su clasificación de los sistemas de valoración de las pruebas judiciales, se incluye de manera independiente el sistema de la apreciación técnico científica o de la cientificidad, acorde con el cual para la averiguación de la verdad en materia penal se debe acudir a las ciencias (medicina, física, sicología, biología, etc.) (Zarazo, 2010). A su vez, otros expositores refieren que la apreciación técnico científica de la prueba penal desde la Ley 600 de 2000, debe llegar a la "época científico-crítica del futuro" (Morales, 2001, pp. 113-114) a la que aludió Enrico Ferri; según eso, el hecho de que la jurisprudencia de la Sala de Casación Penal de la Corte Suprema de Justicia se preocupe por otorgarle a las reglas de la sana crítica un carácter científico, es un acercamiento a los criterios técnico científicos de apreciación de las pruebas penales.

Ahora bien, ¿qué ha dicho la jurisprudencia sobre los criterios técnicos científicos para valorar las pruebas penales en el actual sistema penal acusatorio colombiano? La Corte (Sentencias 24468 de 2006, 26618 de 2007, 26276 de 2007, 28888 de 2008, 29053 de 2008, 28935 de 2009, 30935 de 2009, 33420 de 2010, entre otras) menciona el tema de manera tímida y solo ilustrativa (obiter dictum), al valorar la admisibilidad de las demandas de casación en algunas providencias y, en otros casos, en sentencias de casación, expresa que los juzgadores deben observar los criterios técnicos científicos normativamente determinados en la valoración de cada medio probatorio en particular (art. 380 CPP), so pena de incurrir en una violación indirecta de la ley penal sustancial por error de hecho por falso raciocinio. En este evento, el demandante en casación deberá precisar la norma de derecho procesal que establece los criterios de valoración de la prueba cuya apreciación se cuestiona, señalar cuál o cuáles criterios fueron desconocidos en el caso particular y, agréguese, demostrar la influencia que dicho yerro tuvo en la parte resolutiva de la sentencia.

Además, la expresión 'criterios técnicos científicos para valorar cada medio probatorio', es utilizada por la Corte Suprema de Justicia en las decisiones ya descritas. De forma curiosa, sin embargo, la Corte (Sentencia 24468 de 2006 y Auto 26618 de 2007) reconoce que el denominado método técnico científico es auspiciado por la doctrina (Morales, 2001) y admite que la Ley 906 de 2004 "trató de perfeccionar o dar más realce a la metodología técnico científica para producir y apreciar las pruebas, estableciendo 'reglas' relativas a los distintos medios de conocimiento".

\section{La doctrina y la jurisprudencia penal nacionales sobre la apreciación técnico- científica de la prueba pericial}

Los criterios de apreciación técnico científica o de valoración probatoria de la prueba pericial se encuentran consagrados en el art. 420 CPP; pautas estas 
obligatorias para el juez al momento de la valoración probatoria, sin que ello signifique la existencia de una tarifa legal. No hay una tarifa científica, pues es el juez quien le da el valor a la prueba pericial (Parra, 2002). Los requisitos generales de cientificidad de la prueba pericial son: la idoneidad técnico científica y moral del perito; la claridad y exactitud de sus respuestas; su comportamiento al responder; el grado de aceptación de los principios científicos, técnicos o artísticos en que se apoye el perito; los instrumentos utilizados; $y$, la consistencia del conjunto de sus respuestas.

No obstante, la infalibilidad de la prueba científica está condicionada por muchos aspectos que debe evaluar el juzgador en cada caso específico para determinar su admisibilidad y su rigor científico, por ejemplo, la metodología empleada (Gascón, 2010); la calidad del procedimiento utilizado para elaborar el informe y su corrección científica (realizado por personal calificado y de acuerdo con los protocolos establecidos en la respectiva ciencia); y el margen de error atribuible al perito. A su vez, los criterios para garantizar la adecuada apreciación de la prueba pericial consagrados en el art. 420 CPP son la idoneidad técnico científica y moral del perito (la calidad del procedimiento y la corrección científica); el grado de aceptación de los principios cientificos, técnicos o artísticos en que se apoya el perito (metodología empleada), la claridad y exactitud de sus respuestas; y la consistencia del conjunto de respuestas (avala la idoneidad del perito y al mismo tiempo posibilita evidenciar el margen de error). Por ello, se resalta que el sistema adoptado por el legislador colombiano fue el europeo y no el estadounidense, es decir, no se trata de reglas de admisibilidad sino de valoración probatoria (Fernández, 2012).

Así mismo, se ha dicho que se deben verificar unos criterios respecto del sujeto; el medio de prueba; los principios aplicados; las técnicas, métodos e instrumentos y el dictamen, todos ellos importantes para determinar los "motivos de credibilidad de un dictamen o informe pericial" (Morales, 2001, pp. 123-127). En relación con el sujeto, se constatan la idoneidad técnico-científica y moral del perito; con respecto al medio de prueba, se precisa el lugar preciso en el cual se encontró dicho elemento de prueba, la cantidad de materia examinada por el perito y la naturaleza del elemento de prueba. Además, en lo tocante a los principios aplicados, se verifican principios científicos y los principios de un arte, una profesión o un oficio; en lo relacionado con las técnicas, métodos e instrumentos, se revisa si se empleó una técnica de orientación, de probabilidad o de certeza. Y, en fin, respecto al dictamen, se debe constatar que contenga "la clara descripción de la persona o cosa que haya sido objeto del examen pericial", "la descripción de la técnica o técnicas empleadas para la observación y los análisis", la relación de "los principios aplicados y de su grado de certeza y aceptación", "la relación de inferencias que se pueden obtener" y "la conclusión". Entre otras cosas, se afirma que "la apreciación de las pruebas, en materia penal, no puede dejarse al arbitrio de las reglas de la sana crítica", puesto que "dicha apreciación debe ser una actividad técnico científica, que comprenda la observación, el análisis, la verificación y la evaluación de los motivos de credibilidad y de no credibilidad" (Morales, 2010, p. 128). 
Adviértase que la Defensoría del Pueblo (tomo II, s. f.), trata dichos criterios no como técnicos científicos de apreciación de la prueba, sino como "motivos de credibilidad de una prueba pericial", con lo cual origina una confusión entre estos y los criterios propiamente dichos para la determinación de tales motivos; sin embargo, con un sector doctrinario (Morales, 2010; Bernal, 2005; y, Pabón, 2006) se ocupa del tema de los criterios de valoración probatoria de la prueba pericial de acuerdo con el art. 420 CPP y sobre el particular se manifiesta que se deben reunir estas exigencias:

1) Idoneidad técnico-científica. Se refiere a la profesionalidad (o reconocimiento en el respectivo campo de acción si no tiene título), conocimientos, experiencia o especialización del perito en la ciencia, arte, técnica, oficio o afición en el que se desempeñe.

2) Idoneidad moral del perito. Debe ser honesto, objetivo, imparcial, sin ningún tipo de prejuicio o interés; no debe tener antecedentes penales o disciplinarios que se relacionen en forma directa con su actividad científica o pericial al punto de socavar su credibilidad.

3) Claridad y exactitud de sus respuestas. Deben ser claras y precisas de manera que el juez, entienda los métodos y procedimientos utilizados, sus fundamentos, así como a la conclusión a la que llegó; deberá explicar en un lenguaje sencillo y claro el lenguaje científico o técnico de su ciencia. A propósito, se dice que el conocimiento científico es claro, preciso y comunicable (Bunge, 2007); por ello, debe evitar la vaguedad, la inexactitud y la superficialidad; la correcta comunicación del perito al juez es, pues, condición necesaria para que este pueda realizar después una adecuada valoración de la prueba pericial (Gascón, 2010).

4) Su comportamiento al responder. Se tiene en cuenta la convicción y seriedad de sus respuestas, la no contradicción de sus fundamentos, la claridad conceptual de sus argumentos, la resolución de las dudas que se le planteen y la disposición para responder el interrogatorio de la parte que no lo ofreció.

5) El grado de aceptación de los principios científicos, técnicos o artísticos en que se apoya el perito. El perito debe demostrar que los principios, métodos y procedimientos utilizados para el peritaje, de acuerdo con las orientaciones o corrientes científicas, son vigentes, así como el grado de aceptación por la comunidad científica a la que pertenece; por eso, la sola manifestación del perito sin soporte académico verificable, no es suficiente para cumplir con este requisito. Aquí debe anotarse que la prueba novel en este aspecto se regula por el art. 422 y no por el art. $420 \mathrm{CPP}$, pues no siempre requiere aceptabilidad en la comunidad académica (Chiesa, 1995).

6) Los instrumentos utilizados. Se refiere a las herramientas, las tecnologías y los equipos empleados. 
7) Asimismo, deberá manifestar si la técnica que utilizó es de orientación -conocimiento verosímil-, de probabilidad -conocimiento probable- o de certeza -conocimiento cierto-; el conocimiento científico, no se olvide, es verificable (Bunge, 2007) y las técnicas de verificación evolucionan o se transforman.

8) Consistencia en las respuestas. Se relaciona con la seguridad y solidez de sus manifestaciones y dice relación con la coherencia y conexión entre la conclusión y las inferencias realizadas a partir de los principios e instrumentos utilizados.

A este respecto, se debe señalar que ninguna de las cuatro decisiones de la Sala de Casación Penal de la Corte Suprema de Justicia consultadas sobre la apreciación de la prueba pericial (Sentencias 28862 de 2008, 31795 de 2009, 32868 de 2010 y 39559 de 2013), desarrolla el contenido del art. 420 CPP; no obstante, respecto de ciertos asuntos relativos a la valoración del peritaje se precisa:

a) La prueba pericial debe valorarse de manera racional y de acuerdo con la sana crítica; no de manera incondicional ni de forma mecánica (Sentencias 39559 de 2013 y 31795 de 2009). El objeto de la valoración del juez es el procedimiento que sustenta las afirmaciones del perito y no su conclusión (Sentencia 39559 de 2013, que reitera la Sentencia 32882 de 2012). Recuérdese, como se apuntó antes, que en el sistema estadounidense de acuerdo con la sentencia Daubert el testimonio experto, antes de entrar al proceso, debe superar primero unas reglas de admisibilidad científica (validez científica) enfocadas solo a los principios y la metodología de la ciencia y no sobre las conclusiones que genera. Ello es así, por cuanto la evaluación del peritaje respecto a sus conclusiones tiene su escenario por antonomasia en la etapa de valoración propiamente dicha. Colombia optó en este punto por el sistema europeo, de tal forma que el control de admisibilidad científica ocurre en la etapa de valoración de la prueba, puesto que en la audiencia preparatoria solo está sometida a simples razones de pertinencia (admisibilidad procesal).

Es decir, la evaluación de la prueba pericial sobre los principios y la metodología de la ciencia, no se realiza de forma previa a su práctica en el juicio oral -en la audiencia preparatoria-, sino con posterioridad junto con sus conclusiones; así, gracias al art. $420 \mathrm{CPP}$, su valoración debe ser íntegra de acuerdo con las pautas allí establecidas. Sin embargo, se hace necesario que la doctrina Daubert, tal como la entiende el sistema estadounidense (control de admisibilidad científica en la audiencia preparatoria), sea acogida por el ordenamiento jurídico por la vía de la reforma legislativa para que las reglas de admisibilidad científica, que también contiene el art. 420 ibídem (pero planteadas de forma exclusiva como reglas de valoración), se realicen de modo previo en la audiencia preparatoria y solo se practique en el juicio oral aquella prueba pericial que cumpla con los criterios de admisibilidad (test Daubert). Se puede decir, entonces, que lo manifestado por la Corte en el sentido de que el objeto de la apreciación del juez es el procedimiento que sustenta las afirmaciones del perito y no su conclusión (Sentencia 39559 de 
2013), es una interpretación errada de la sentencia Daubert (implícita) que solo se refiere a condiciones de admisibilidad y no de valoración.

b) Cualquier descubrimiento o hallazgo de la ciencia, además de someterse a la crítica racional, con independencia de su aceptación general y vigencia en el respetivo campo científico, puede ser refutada por la experiencia delimitándose su carácter científico o metafísico (Sentencia 39559 de 2013). Esta razón, con base en Popper (1980), la adujo para darle validez al empirismo como método para valorar las conclusiones científicas de un perito. No obstante, de la sentencia 39559 (2013), se infiere que los testimonios de los peritos (psicólogo y psiquiatra), perdieron poder suasorio, por cuanto sus respuestas y conclusiones, que por ejemplo se relacionaban con el hecho de que la procesada no tendía al engaño o a la mentira, o que desconocía que se encontraba incursa en un delito, se encontraba refutada a través de otros medios de prueba; la Corte, pues, no examinó esta circunstancia lo que habría originado un desarrollo interesante de la aplicación y alcance concreto de los criterios de valoración de la prueba pericial psicológica y psiquiátrica a partir del art. 420 CPP.

\section{Estudios sobre la valoración del peritaje psicológico en delitos sexuales contra menores en Colombia}

Al respecto, debe decirse que las referencias disponibles se pueden clasificar en dos grupos: en el primero, se encuentran aquellos textos que, si bien desarrollan el tema del valor de la prueba pericial psicológica en delitos sexuales contra los menores, lo hacen desde el concepto de valor como "alcance de la significación o importancia de una cosa" (Real Academia Española, 2013); la mayoría de estos escritos son realizados por psicólogos jurídicos.

Con el segundo, se relaciona un documento que realiza una aproximación sobre la valoración del peritaje psicológico en delitos sexuales contra menores. Recuérdese que, en este último evento, se entiende por valoración la operación mental que realiza el juez para determinar el mérito que pueda tener la prueba que le dará el respectivo convencimiento (Devis, 1984), la que se encuentra en una grada previa a esa fase última de la etapa de juzgamiento (De Miranda, 2012). Precisamente, la eficacia probatoria o fuerza de convición del peritaje psicológico estará refrendada por la aplicación del artículo 420 CPP que establece los criterios de valoración probatoria de la prueba pericial.

\section{El valor de la prueba pericial en el proceso penal. Una óptica psicológica jurídica.}

Las distorsiones del testimonio infantil de abuso sexual por ser víctimas predispuestas, participantes, falsas y provocativas, por el erotismo infantil, por la manipulación de parientes que inducen al menor de edad a distorsionar su declaración o por inadecuadas técnicas de entrevistas, pueden ser contrarrestadas con evidencia científica como lo es la psicología forense (Tapias, 2008). Por ello, en el plano internacional los procesos penales han sido reformados en protección del interés del 
menor de edad para elevar la calidad de las pericias psicológicas, entre las cuales están: la autorización para la recepción de la declaración; la grabación en circuito cerrado de la declaración; la admisión de los testimonios de oídas; la capacidad del menor de edad para rendir testimonio; las salas de audiencias especiales; el control judicial del interrogatorio realizado por las partes en el proceso penal; el apoyo a la víctima por parte de personas que le generen confianza; las audiencias privadas; y la representación judicial de la víctima (Myers, 1996). Es más, dentro de las técnicas para las "estrategias de evaluación psicológica forense en procesos de abuso sexual" se encuentran el protocolo de entrevista de Michigan, el uso de la casa de muñecas, el uso de láminas de cuerpos, el uso de muñecos sexuados y la entrevista cognoscitiva. Salvo el protocolo de Michigan, todas desaconsejadas (Tapias, 2008).

Adviértase, además, que el Protocolo de Michigan diseñado por la Agencia para la Independencia de la Familia "FIA" del Estado de Michigan USA, es un modelo de entrevista forense para menores de edad en investigaciones de abuso sexual; en Michigan, este protocolo se usa de manera conjunta con el "Protocolo Modelo de Abuso al Menor-Metodología Coordinada del Equipo de Investigación", del Grupo de Trabajo del Gobernador para la Justicia del Menor. Su propósito consiste en mejorar las entrevistas para minimizar posibles traumas a los menores de edad, originar una mayor credibilidad en la información recaudada y garantizar los derechos del procesado. La entrevista contiene nueve etapas: preparar el entorno de la entrevista, la presentación, competencia legal (verdad/mentira), establecer la regla de base, completar el rapport con una entrevista de práctica, introducir el tema, narrativa libre, interrogatorio y clarificación, y cierre. Asimismo, el protocolo desarrolla temas especiales como preguntas acerca del tiempo, las ayudas para le entrevista (constituyen "un problema porque son modelos que representan algo") y los niños con necesidades especiales (preescolares, niños bilingües, deficiencias visuales, deficiencias auditivas, comunicación aumentativa y alternativa y discapacidades evolutivas) (Michigan, 1998).

Además, el psicólogo forense no tiene por objeto el estudio de la honestidad y la moral de una persona ni tampoco puede valorar la veracidad de los hechos, sino que es un perito capaz de evaluar la credibilidad de una declaración. Por lo tanto, son improcedentes las solicitudes judiciales o de parte para que se determine si el menor de edad dice la verdad, o si el imputado es deshonesto o si el niño es mitómano. Las solicitudes deben ir dirigidas al experto para que se pronuncie sobre la credibilidad de un relato en particular. La técnica para evaluar la credibilidad y la validez recomendable es aquella que tiene como indicadores las expresiones verbales. Por eso, la más recomendable es la técnica de Análisis de Contenido Basado en Criterios (ACBC o CBCA).

A este instrumento se ha incorporado un protocolo denominado SVA (Statement Validity Assesment) para asistir el análisis de validez del testimonio (Tapias, 2008). El Statement Validity Assessment (SVA) (Evaluación de la Validez de la Declaración), es la técnica más empleada para evaluar la veracidad de las declaraciones verbales. El SVA, se desarrolló en Alemania y se sustentó en la experiencia clínica de diver- 
sos psicólogos. Alrededor de 1950, Udo Undeutsch realizó la primera descripción del SVA y, con posterioridad, fue modificada hasta su forma actual por Steller y Köhnken (1989) y Raskin y Esplin (1991). En un principio, el SVA se desarrolló para valorar las declaraciones verbales de niños que habían sido víctimas de abuso sexual.

Sin embargo, en años recientes se ha intentado validar y generalizar la aplicación de este instrumento a adultos. A pesar de que es un instrumento muy utilizado en el ámbito forense como prueba psicológica, no se le debe considerar un test o una escala estandarizada, sino un método semi-estandarizado para la evaluación de la credibilidad de las declaraciones. El desarrollo del SVA está fundamentado en lo que Steller (1989) denomina la hipótesis de Undeutsch. De acuerdo a ella, un testimonio basado en una experiencia real difiere en cuanto a su calidad y contenido de un testimonio basado en un acontecimiento imaginado. El SVA, adviértase, está formado por tres componentes que son dependientes entre sí: a) una entrevista estructurada con la víctima, b) el CBCA que evalúa el contenido de la declaración de la persona; y, c) la integración del CBCA con la información derivada de un set de preguntas denominado Lista de Validez, el cual combina la información extraída del análisis del contenido de la declaración con otra información relevante del caso y con la pesquisa obtenida a partir de la exploración de la entrevista o entrevistas previamente realizadas (Godoy-Cervera \& Higueras, 2005).

Por otra parte, los protocolos más usados en la obtención de testimonios infantiles, que "actúan como guías, como instructivos, más no como técnicas ni instrumentos de evaluación per se", son la 'entrevista paso a paso', la 'guía de Poole y Lamb-Protocolo de Michigan', el 'Protocolo NICHD', la 'entrevista de Corner House SATAC-RATAC' y la 'entrevista cognitiva'”' (Espinosa, 2011, pp. 209-214); su objetivo es señalar al entrevistador cómo debe realizarse la toma de un testimonio, de manera que no le permite determinar la credibilidad de la declaración, ni al psicólogo realizar un diagnóstico psicológico o una evaluación psicológica forense (Espinosa, 2011).

A este respecto, recuérdese que la entrevista de Corner House es una guía para la realización de pesquisas con menores de edad, presuntas víctimas de abuso sexual (Espinosa, 2011). Según la ICITAP (2007), el proceso de entrevista SATAC está compuesto por las siguientes etapas: "[s]impatía ("rapport"). El propósito es el establecimiento de la comodidad, la comunicación y la competencia (según el desarrollo cognitivo y las habilidades del niño). Identificación de anatomía. Tiene dos propósitos: para determinar el entendimiento del niño y su habilidad de distinguir entre los sexos, y para llegar a un idioma común referente a los nombres de las partes del cuerpo. La indagación del tacto o de toques. El propósito es el ensayo de la habilidad del niño para entender y comunicar acerca de los toques que recibe y da. Escenario del abuso. Hay dos propósitos: permitir a la niña relatar los detalles de su experiencia, y explorar hipótesis alternativas. Clausura o cierre. Hay tres propósitos: educar a la niña con relación a su seguridad personal, explorar opciones de seguridad con la niña, y proveer un fin respetable a la entrevista. 
La entrevista SATAC es un proceso semiestructurado, por lo cual una o más de estas etapas puede ser modificada o eliminada permitiendo las consideraciones relacionadas al desarrollo y/o la espontaneidad de cada niño. La ICITAP es una de las Oficinas de Capacitación de Investigadores Penales y Expertos Forenses, que conforma el Programa de Reforma al Sector de la Justicia PRSJ, que desarrolló en Colombia el Departamento de Justicia DOJ de los Estados Unidos de América (Embajada de los Estados Unidos de América, 2014).

Por ello, al tratar sobre la estructura del dictamen pericial psicológico, se propone que el informe final tenga los siguientes elementos (Saade \& Rojas, 2012): el motivo de la peritación; las técnicas utilizadas en la evaluación (entrevista estructurada, estudio del expediente, pruebas psicológicas aplicadas, etc., estas últimas son un instrumento de medición del comportamiento humano que se emplea para realizar evaluaciones científicamente válidas y confiables, llamadas también test psicológicos: Oyuela (2011). A lo anterior se debe añadir: La información del evaluado; la descripción de los hechos; la historia familiar y personal; el examen mental; los antecedentes psíquicos y físicos; los resultados; la discusión; y la conclusión. Es más, se sugiere que se empleen instrumentos de medición válidos y confiables y que se introduzcan citas bibliográficas para acostumbrar a los jueces y a las partes, inclusive a los mismos peritos, en el sentido de que no es la postura del psicólogo sino la opinión aceptada por la comunidad científica a la que pertence, la que allí se plantea.

Este texto, si bien no tiene un sentido probatorio desde el punto de vista jurídico procesal, de manera general y coincidente desarrolla las características que debe tener un peritaje psicológico a la luz del art. 420 de la Ley 906 de 2004; por supuesto, materiales como estos, pero construidos con mayor especialidad y rigurosidad, ayudarían a elaborar estudios jurídicos sobre la forma como deben valorarse probatoriamente por parte del juez la prueba pericial psicológica en cada caso particular. Es claro que con antelación a la implantación del sistema penal acusatorio en Colombia, el valor de la pericia psicológica ha sido mínimo y solo se utilizaba cuando no existía evidencia física sobre delitos sexuales y, en otros eventos, los psicólogos ejercían el papel de simples receptores de denuncias (Tapias et al, 2009). Esto en contraposición a lo que sucede en Canadá, donde los peritos psicólogos en los delitos sexuales contra menores de edad, pueden ser citados como expertos para entender el comportamiento humano, establecer hechos pasados o realizar predicciones, refutar otros peritajes, declarar sobre el estado del conocimiento de su ciencia o, simplemente, responder a preguntas hipotéticas.

Por eso, decisiones como la Sentencia 23706 de 2006 que refleja "el avance de la producción científica psicológica" para abordar los casos de delitos sexuales frente al testimonio y al peritaje, deben ser tenidas en cuenta; en ella, durante la vigencia de la Ley 600 de 2000, la Corte se ocupó de un caso de abuso sexual cometido contra una niña. Allí, se sostiene que, a partir del peritaje psicológico, se puede determinar si un niño se encuentra en capacidad de establecer si pudo percibir lo sucedido; sin duda, este pronunciamiento coincide con los avances de psicología 
forense sobre la credibilidad del testimonio en el que se han diseñado técnicas como el Análisis de Contenido Basado en Criterios (CBCA) y, bien ha dicho la doctrina, las declaraciones de las víctimas menores de edad de delitos sexuales pueden ser validadas por un perito en psicología forense (Tapias et al., 2009).

Debe aclarase que la Sentencia 23706 de 2006, tuvo tres salvamentos de voto: en el primero, suscrito por el magistrado Espinosa Pérez, se dice que el peritaje psicológico resulta de gran apoyo para valorar el testimonio del menor de edad víctima de abuso sexual, y enlista las pseudomentiras -infantil, negligente, pasional, ficticia o imaginativa y fabuladora- y advierte, además, que las declaraciones de los niños deben analizarse con mayor prudencia debido a las diversas clases de influencia que los lleva a equivocar la realidad con la fantasía. La mayoría de la Sala de la Corte señala, en la fundamentación de la sentencia, que la práctica de un dictamen psiquiátrico sobre la sanidad mental no es condición para la confiabilidad del testimonio del menor de edad; frente a esto el magistrado Espinosa Pérez afirma que, si bien la pericia psicológica no es requisito sine qua non, sí es de gran ayuda para la valoración de dicha declaración.

A su turno, al analizar la forma como se valora la prueba pericial psicológica, también la doctrina (Solórzano, 2011) estudia algunos fallos de la Corte Constitucional y la Corte Suprema de Justicia proferidos en casos de abuso sexual contra menores de edad; sin embargo, lo que realmente se hace es plasmar comentarios sobre el papel del psicólogo y la importancia de la prueba pericial psicológica en el proceso penal; por ello, estas exposiciones no describen la forma como fue valorado en dichos casos el peritaje psicológico desde el punto de vista jurídico procesal; esto es, si se observaron o no los criterios técnico científicos de acuerdo con el artículo 420 de la Ley 906 de 2004 descritos en capítulo anterior.

Así mismo, se citan (Solórzano, 2011) tres decisiones judiciales de las cuales se transcriben unos apartes para concluir que la prueba pericial psicológica no ha adquirido la importancia que requiere en los procesos penales: la Sentencia T-048 de 2005 (Corte Constitucional); una sentencia del Tribunal de Bogotá -sin referencia-; y la Casación 32595 de 2009 (Sala Penal de Casación Penal, Corte Suprema de Justicia). Es de anotar que, en ninguno de los tres casos, se decretó o practicó dictamen psicológico alguno; luego, ni el tribunal ni las altas Cortes valoraron dicha prueba, porque simplemente no existieron en tales instancias judiciales.

No obstante, se estima que ha habido avances en punto de la importancia de la prueba psicológica, pues la Corte Suprema de Justicia así lo reconoció (Sentencias 10615 de 1999 y 23706 de 2006). No obstante, la primera sentencia se expide bajo la vigencia del Decreto 2700 de 1991 y, la segunda, en el marco de la Ley 600 de 2000 (códigos procesales penales anteriores a la Ley 906 de 2004). Para culminar, se acude a un estudio realizado por un estudiante de la Maestría de Psicología Jurídica de la Universidad Santo Tomás, dirigido por el estudioso mencionado (Solórzano, 2011), destinado al examen de los primeros cincuenta fallos proferidos en el país sobre delitos sexuales en el cual se concluye, de nuevo, que la prueba pericial 
psicológica para fundamentar las decisiones judiciales no ha recibido la importancia que se merece. También, a propósito de lo anterior, debe relacionarse un trabajo de grado del año 2009 realizado en la Maestría en Psicología Jurídica de la Universidad Santo Tomás (Gamba, Mejía \& Murillo, 2009), que tenía como objetivo general identificar la apreciación de la prueba psicológica por parte de los magistrados en las sentencias analizadas; empero, debido al enfoque de la misma y a la profesión de los investigadores, no identifica la apreciación probatoria de la prueba pericial psicológica a la luz del Código de Procedimiento Penal. No es, pues, un estudio procesal penal de valoración probatoria.

De igual forma, la Agencia de los Estados Unidos para el Desarrollo Internacional (USAID) y la Defensoría del Pueblo de Colombia editaron un texto (Espinosa, 2012), dividido en tres unidades temáticas: la primera, sobre "El abuso sexual: víctimas y agresores"; la segunda, se intitula "Acerca de los diferentes abordajes al interior de la psicología forense" y; la tercera, que se llama: "Referentes de interés en delitos sexuales". En esta última unidad, se desarrolla un subcapítulo denominado "Revisión jurisprudencial sobre delitos sexuales", en el que se diseña una matriz de la jurisprudencia de la Corte Constitucional y la Sala de Casación Penal de la Corte Suprema de Justicia en materia de delitos sexuales relacionada con "la tipicidad, los bienes jurídicos protegidos, la violencia, el consentimiento de la víctima, la responsabilidad de los autores y la valoración de las pruebas" (p. 108).

Ahora bien, en relación con la problemática de la valoración de las pruebas por parte de la jurisprudencia de la Corte Suprema de Justicia, en la mayoría de los casos realizando la trascripción de unos apartes, Espinosa (2012) examina los fallos de casación 32595 de 2009, 32103 de 2009 y 28742 de 2008 sobre cámara Gesell; también, las providencias 31950 de 2009 y 32868 de 2010 sobre entrevistas a menores de edad. Además, las sentencias de casación 32595 de 2009, 31950 de 2009, 32868 de 2010 y 32103 de 2009 sobre la idoneidad del perito; las providencias de casación 23706 de 2006, 24468 de 2006, 27946 de 2007, 28274 de 2007, 28511 de 2007, 28742 de 2008, 32103 de 2009, 32268 de 2012 y 31950 de 2009 sobre la credibilidad del testimonio del menor de edad y la Sentencia 32868 de 2010 sobre protocolos. Este estudio, adviértase, no aborda la apreciación técnico-científica de la prueba pericial psicológica en sentido jurídico procesal penal. En términos generales, no es un trabajo de la aplicación o interpretación del art. 420 de la Ley 906 de 2004 referido a la jurisprudencia penal colombiana, pero, de todas maneras, brinda información y conceptos valiosos desde el punto de vista de la psicología jurídica que ilustra ese complemento interdisciplinario que requiere la apreciación técnico-científica de la prueba pericial psicológica.

En esencia, pues, los trabajos mencionados solo analizan el valor, entendido este como la importancia del papel del psicólogo jurídico o forense y de la prueba psicológica en los procesos del sistema penal acusatorio, pero no tratan ni desarrollan o pretenden realizar un estudio, general o específico, de los criterios de valoración probatoria establecidos en el art. 420 CPP para la prueba pericial ni, mucho menos, el peritaje psicológico en los casos de delitos sexuales contra niños, 
niñas y adolescentes. No obstante, tampoco es el propósito de este trabajo disertar sobre los aspectos teóricos y metodológicos de la evaluación psicológica del abuso sexual contra menores de edad.

\section{La apreciación técnico científica de la prueba pericial psicológica en delitos sexuales contra menores. Una valoración a la luz del art. 420 CPP.}

Al respecto, algún estudioso se ocupa de la pericia psicológica argumentando que, en el ámbito jurídico probatorio, se pueden abordar diversos aspectos por las ciencias que estudian el comportamiento humano, relacionadas tanto con la conducta y la personalidad del procesado como con la de las víctimas y los testigos. Incluso, se definen los test psicólogicos como "instrumentos que permiten la determinación y evaluación de diferentes aspectos mentales y comportamentales de la persona a quien se aplican" (Pabón, 2006, p. 451), los cuales pueden estar precedidos -en el campo pericial- de entrevistas con la persona evaluada. Los tests son los siguientes: el de escala Wechsler-Bellevue; el de Rorschach; el de Bender; el de Apreciación Temática-TAT, y el de Gráficos. Asimismo, se describen los cuestionarios dentro de los que se encuentran el inventario de ansiedad Estado-Rasgo-STA; el inventario de depresión de Beck-BDI; la escala de gravedad de los síntomas del trastorno postraumático; y la escala de autoestima de Rosemberg e Inventario " $\mathrm{Mi}$ llón de Estilos de Personalidad-MYPS".

Además, se recomiendan las siguientes reglas a tener en cuenta para la presentación y recepción de informes, indicando que el perito debe: a) respetar el lenguaje del examinado al declarar sobre los exámenes y pruebas practicadas; b) relacionar las citas que le sirvieron de fundamento para la elaboración del dictamen y la técnica empleada en la base de la opinión pericial; c) presentar su dictamen de manera clara y sencilla; d) abarcar todos los exámenes, los tests aplicados y demás estudios que se hayan practicado; e) contener los diagnósticos diferenciales y el estado mental del examinado, así como los efectos respectivos a sus conclusiones. Finalmente, se añade que el interrrogatorio puede relizarse sobre la entrevista psicológica del examinado.

También, se recomienda (Pabón, 2006) que los test se combinen con otros métodos y procedimientos para garantizar una mayor objetividad y unas conclusiones imparciales y completas sobre el asunto; su aplicación, se dice, depende de lo que se busque demostrar (prueba de carácter o la investigación de una cuestión psicológica como la determinación de credibilidad de un testigo) y su descripción se debe realizar de manera circunstanciada para que se pueda realizar un examen crítico de sus resultados. Por último, se trata sobre la pericia psicólogica, sobre síndromes de victimización como los de la mujer maltratada, del niño abusado, del niño maltratado y del trauma de la persona violada. No obstante, si bien esas elaboraciones realizan una aproximación a la prueba pericial psicológica en el campo jurídico penal procesal, también es cierto que debido a la generalidad de los conceptos no se vislumbra su conexión directa con el tratamiento específico de los criterios de apreciación técnico científicos consagrados en el art. 420 CPP. 
En fin, retomando las cuatro decisiones de la Corte Suprema de Justicia ya referenciadas, debe decirse que solo tres de ellas se refieren a delitos sexuales cometidos contra menores de edad (Sentencias 31792 de 2009, 32868 de 2010 y 39559 de 2013). En la Sentencia 39559 de 2013, si bien se hace hace referencia a un peritaje psicológico y a otro psiquiátrico, esos fueron realizados a la acusada y fueron desestimados sin que se hubiese hecho la valoración aplicando de forma estricta los criterios consagrados en el art. 420 CPP. Por otro lado, la Ley 1652 de 2013 regula la entrevista forense de menores de edad víctimas de delitos sexuales, pero, en principio, esta entrevista forense no es un peritaje ni tampoco los profesionales o entrevistadores especializados que la realizan, según el caso, acudirían al juicio oral como peritos. Estos lo harían como testigos de acreditación. Tal como lo establece la Ley 1652, dicha entrevista solo es un elemento material probatorio que puede ser introducido al juicio oral a través de los servidores que la recaudaron y que es admisible como prueba de referencia y apreciada por el juzgador en ese sentido. De modo que los criterios de valoración no se encuentran regulados por el art. 420 CPP, sino por el art. 441 que remite a la testimonial (art. 404) y a la documental (art. 432).

La Corte Constitucional (Sentencia C-177 de 2014), a su vez, declaró exequible el articulado de la Ley 1652 de 2013, con el argumento de que las entrevistas forenses deben ser realizadas por especialistas del comportamiento humano, psicólogos, profesionales en desarrollo familiar, trabajadores sociales y profesionales afines, entre otros, con el propósito de "fortalecer la fiabilidad de las manifestaciones del menor". En este caso, si el entrevistador, al momento de realizar la entrevista, por ejemplo, utiliza "estrategias de evaluación psicológica forense en procesos de abuso sexual" (Tapias, 2008), deberá analizarse cada caso concreto para determinar si actuó en calidad de simple testigo de acreditación, de testigo técnico o de perito, pues, en este último evento, el peritaje como tal se deberá valorar en el marco del art. 420 CPP.

\section{Conclusiones}

Así las cosas, llegados a esta altura de la exposición, debe decirse lo siguiente:

El caso Daubert $v$. Merrell Dow Pharmaceuticals, es la referencia internacional más importante en materia de prueba científica, porque constituye "un mínimo tratado de epistemología" (Taruffo, 2012); esta sentencia de la Corte Suprema de Justicia de los Estados Unidos ha fijado, de forma general, unos criterios de admisibilidad científica para que un experto o científico rinda testimonio en el juicio oral. Estas pautas son las siguientes: a. La prueba debe ser relevante; b. La prueba debe ser fiable; c. La teoría o técnica científica en la que se basa la prueba debe ser verificada o probada para determinar si puede ser falsificada; d. La teoría o técnica en la que se basa la prueba es la verificación de revisión por sus pares o de publicación; e. Debe considerarse el conocido o potencial margen de error de la técnica científica utilizada; y f., la aceptación general de la comunidad científica de los principios y la metodología en que se apoya la prueba pericial, sin que esta 
sea una condición sine qua non de admisión. Esta evaluación de admisibilidad del testimonio experto es pertinente solo para los principios y la metodología de la ciencia, no para las conclusiones que genera. De esta manera, el caso Daubert establece reglas de admisibilidad científica previas al juicio oral y no de valoración de la prueba pericial.

Desde otra perspectiva, la Ley 906 de 2004 optó por el modelo europeo o de civil law para el respectivo control a la prueba pericial. El europeo, es el control que se desarrolla en la etapa de valoración de la prueba dado que previamente solo está sometida a simples razones de pertinencia (admisibilidad procesal). El estadounidense, es el control de admisibilidad (validez científica) anterior al juicio oral en la aplicación de los requisitos del caso Daubert. Al mencionarse el control de admisibilidad de la prueba científica antes de su práctica o previo al juicio en el sistema penal acusatorio colombiano, se hace referencia de forma exclusiva al control que se realiza en la etapa intermedia de preparación del juicio, esto es, a la audiencia preparatoria (en principio la puerta de entrada de los medios de prueba al proceso para hacerlos valer en el juicio oral), que difiere del control de admisibilidad de la prueba pericial en el juicio oral o durante su práctica. En todo caso, el control previo que se realiza en Colombia en la audiencia preparatoria es solo procesal y no científico

De igual manera, los criterios de valoración probatoria o técnico-científicos no configuran tarifa legal alguna, pues el juez es quien en últimas le otorga a la prueba pericial el poder suasorio o la fuerza probatoria que le corresponda, precisamente a través de la verificación de las pautas de cientificidad descritas. La tendencia en los actuales procesos judiciales es hacer menos referencia a las máximas de la experiencia, el sentido común y la cultura media, y, con más frecuencia, a la ciencia como tipo de conocimiento para resolver problemas que desbordan la cultura del hombre común (Taruffo, 2014).

También, a la luz del art. 420 de la Ley 906 de 2004 no existe literatura específica en sobre la prueba pericial psicológica en delitos sexuales contra menores de edad en sentido jurídico probatorio; por ello, se hace necesario adelantar estudios para que desde el punto de vista doctrinario se establezcan guías que sirvan de apoyo a los profesionales del derecho en el ejercicio de la valoración técnico-científica.

Además, aquí se propone que la doctrina Daubert, tal como es entendida por el sistema estadounidense (control de admisibilidad científica en la audiencia preparatoria), sea acogida por el ordenamiento jurídico por la vía de la reforma legislativa para que las reglas de admisibilidad científica -que también contiene el art. 420 CPP, pero como reglas de valoración en forma exclusiva- se consideren en la audiencia preparatoria y solo se practique en el juicio oral aquella prueba pericial que cumpla con los criterios de validez científica (test Daubert). Esto es, que la evaluación de admisibilidad científica en la audiencia preparatoria se realice solo sobre los principios y la metodología de la ciencia y no en torno a las conclusiones que genera, dado que la evaluación sobre estas debe realizarse en la etapa de valoración probatoria por parte del juez. 


\section{Referencias}

Allen, R. J. (2012). El desafío conceptual de la prueba pericial. En M. Bustamante, Derecho probatorio contemporáneo. Prueba científica y técnicas forenses (trad. O. Vargas) (pp. 215-239). Medellín: Universidad de Medellín.

Andrés, P. (2009). Sobre prueba y motivación. En M. Monje, Consideraciones sobre la prueba judicial (pp. 47-96). Madrid: Fundación Coloquio Jurídico Europeo Madrid.

Auto 26618 (2007, enero 24). Casación. M. P. Álvaro Orlando Pérez Pinzón. Sala de Casación Penal, Corte Suprema de Justicia.

Auto 28888 (2008, febrero 13). Casación. M. P. Julio Enrique Socha Salamanca. Sala de Casación Penal, Corte Suprema de Justicia.

Auto 29053 (2008, noviembre 5). Casación. M. P. José Leonidas Bustos Martínez. Sala de Casación Penal, Corte Suprema de Justicia.

Auto 30935 (2009, septiembre 16). Casación. M. P. José Leonidas Bustos Martínez. Sala de Casación Penal, Corte Suprema de Justicia.

Auto 33420 (2010, mayo 12). Casación. M. P. Yesid Ramírez Bastidas. Sala de Casación Penal, Corte Suprema de Justicia.

Auto 36784 (2012, septiembre 17). Casación. M. P. AA.VV. Sala de Casación Penal, Corte Suprema de Justicia.

Bedoya, L. (2008). La prueba en el proceso penal colombiano. Fiscalía General de la Nación, Escuela de Estudios e Investigaciones Criminalísticas y Ciencias Forenses. Recuperado de http://www.fiscalia.gov.co/en/wp-content/ uploads / 2012/01/LaPruebaenelProcesoPenalColombiano.pdf

Berger, M. (2011). The Admissibility of Expert Testimony. Federal Judicial Center. National Research Council. Recuperado de http://www.fjc.gov/public/pdf. nsf/lookup/SciMan3D01.pdf/\$file/SciMan3D01.pdf

Bernal, B. (2005). Técnicas de Investigación Criminal en el Sistema Acusatorio. Bogotá: Andrés Morales.

Breyer, S. (2011). Introduction. Federal Judicial Center. National Research Council.. Recuperado de http://www.fjc.gov/public/pdf.nsf/lookup/SciMan3D01. pdf/\$file/SciMan3D01.pdf

Bunge, M. (2007). La ciencia, su método y su filosofía. Bogotá: Ediciones Akerena.

Chiesa, E. (1995). Derecho Procesal Penal de Puerto Rico y Estados Unidos (Vol. III). Bogotá: Forum. 
Comisión Intersectorial para el Seguimiento del Sistema Penal Acusatorio. Actas de la Comisión Redactora del SPA. (2014). Comisión Intersectorial para el Seguimiento del Sistema Penal Acusatorio. Recuperado de http:/ / cispa.gov. co $/$ index.php?option $=$ com_docman\&Itemid $=46$

Corporación Excelencia en la Justicia. (2010). Carga de los defensores públicos en el sistema penal acusatorio. Recuperado de http://www.cej.org.co/index.php/ justiciometros3 / 2314-carga-de-los-defensores-publicos-en-el-sistema-penalacusatorio

Cuello, G. (2008). Derecho probatorio y pruebas penales. Bogotá: Legis.

Daubert v. Merrel Dow Pharmaceuticals, Inc. -509 U.S. 579 (1993). Corte Suprema de Justicia (1993, 28 de junio), Estados Unidos. Recuperado de http: / / supreme. justia.com/cases / federal/ us /509/579/ case:html

De Miranda, C. (2012). ¿Es realmente el juez el peritus peritorum? En M. Bustamante. Derecho probatorio contemporáneo. Prueba científica y técnicas forenses (pp. 293-309). Medellín: Universidad de Medellín.

Decreto 1345 de 1970. Por el cual se codifican las normas sobre Procedimiento Penal. Diario Oficial No. 33.139, septiembre de 1970. Recuperado de ftp:/ / ftp. camara.gov.co/camara/basedoc/decreto/1970/decreto_1345_1970.html\#

Decreto 409 de 1971. Por el cual se introducen reformas al Código de Procedimiento Penal y se codifican todas sus normas. Diario Oficial No. 33.303, mayo de 1971. Recuperado de ftp://ftp.camara.gov.co/camara/basedoc/decreto/1971/ decreto_0409_1971.html

Decreto 50 de 1987. Por el cual se expide el Código de Procedimiento Penal. Diario oficial No. 37.754, enero de 1987. Recuperado de ftp://ftp.camara.gov.co/ camara/basedoc/decreto/1987/decreto_0050_1987.html

Decreto 2700 de 1991. Por medio del cual se expiden y se reforman las normas de procedimiento penal. Diario Oficial No. 40.190, noviembre de 1991.

Defensoría del Pueblo. (s. f.). Plan Nacional de Capacitación-Sistema Nacional de Defensoría Pública (T. I). Bogotá: Imprenta Nacional.

Defensoría del Pueblo. (s.f.). Plan Nacional de Capacitación-Sistema Nacional de Defensoría Pública (T. II). Bogotá: Imprenta Nacional.

Denti, V. (1972). Cientificidad de la prueba y libre valoración del juzgador. Boletín Mexicano de Derecho Comparado (trad. S. Oñate) (pp. 3-22). México: Universidad Autónoma de México.

Devis, H. (1971). Cientificidad de la prueba, en relación principalmente con los dictámenes periciales, y la libertad de apreciación del juzgador. Revista de la Universidad Externado de Colombia, 12(2), 141-172. 
Devis, H. (1984). Compedio de la prueba judicial. Anotado y concordado por Adolfo Alvarado Velloso (Vol. I). Buenos Aires: Rubinzal- Culzoni.

Espinosa, A. (2011). La psicología del testimonio. En G. Hernández, Psicología Jurídica Iberoamericana (pp. 197-230). Bogotá: Manual Moderno.

Espinosa, A. (2012). Aportes de la psicología forense al abordaje de los delitos sexuales. Defensoría del Pueblo, Bogotá: Stilo Impresores Ltda.

Estados Unidos de América. (2014). Programa de Reforma al Sector de la Justicia. Bogotá: Embajada de los Estados Unidos de América. Recuperado de http:/ / spanish.bogota.usembassy.gov/doj.html

Falcón, E. (2012). La prueba científica. Revista Instituto Colombiano de Derecho Procesal (38), 219-257.

Federal Evidence Review. Highlighting Recent Federal Evidence Cases and Developments. (2014). Federal Rules Of Evidence (2014). Recuperado de www. federalevidence.com: http: / / federalevidence.com/rules-of-evidence\#Rule402

Federal Judicial Center. National Research Council. (2011). Reference Manual on Scientific Evidence. Third Edition. Recuperado de www.fjc.gov: http:/ / www.fjc. gov/public/pdf.nsf/lookup/SciMan3D01.pdf/\$file/SciMan3D01.pdf

Fernández, M. (2012). Valoración judicial y reglas probatorias. En M. Bustamante. Derecho probatorio contemporáneo. Prueba científica y técnicas forenses (pp. 55-75). Medellín: Universidad de Medellín.

Ferrer, J. (2006). Estudios sobre la prueba. México: Universidad Nacional Autónoma de México.

Ferreyra de la Rúa, A. \& Bella, G. (2008). Prueba científica. Examen de ADN y otros análogos. Inspección corporal. En R. Arazi. Temas de prueba. Prueba ilícita y prueba científica (pp. 33-71). Buenos Aires: Rubinzal Culzoni.

Fiscalía General de la Nación. (2009). Manual de Procedimientos de la Fiscalía en el Sistema Penal Acusatorio. Recuperado de http:/ / www.fiscalia.gov.co/colombia/ wp-content/uploads/2012/03/spoa.pdf

Gamba, V., Mejía, A. W. \& Alfonso, C. (2009, septiembre). Análisis de sentencias de tribunales superiores y Corte Suprema de Justicia con respecto a la prueba psicológica referente a delito sexual en menor de edad a partir de la entrada en vigencia del sistema penal acusatorio, (Tesis de Maestría). Bogotá: Facultad de Psicología Maestría en Psicología Jurídica, Universidad Santo Tomás.

Gascón, M. (2010). Prueba científica: Mitos y paradigmas. Anales de la Cátedra Francisco Suárez, (44) 81-103. 
Godoy-Cervera, V. \& Higueras, L. (2005). El análisis de contenido basado en criterios (CBCA) en la evaluación de la credibilidad del testimonio. Recuperado de http: / / www.papelesdelpsicologo.es/vernumero.asp?id=1249

Gozaíni, O. (2012). La prueba científica no es prueba pericial. Revista del Instituto Colombiano de Derecho Procesal (38), 201-215.

González, J. (agosto 11 de 2014). [Comunicación personal]. Copia en posesión de Juan José Cantillo Pushaina.

Granados, J. (2005). La prueba pericial y la prueba novel en el marco del nuevo proceso penal en Colombia. Derecho penal contemporáneo (11), 75-98.

Hernández, L. (2010). Asimetría en el acceso a la justicia: Un paralelo entre la defensa privada y pública a partir del nuevo sistema penal acusatorio. Bogotá: Universidad Javeriana. Recuperado de http://www.javeriana.edu.co/juridicas/pub_rev/ univ_est/documents/2asimetria.pdf

ICITAP, Colombia. (2007). Curso de entrevistas forenses a niños y su preparación para el juicio. Protocolo SATAC (RATAC, Finding Words).

Jiménez, F.; Sáchica, C. \& Moya, M. F. (2009). Sistema Procesal y Metodología de investigación criminal. Defensoría del Pueblo, Colección Sistema Penal Acusatorio (T. II). Bogotá: Alianza Service Ltda.

Jiménez, F. (2012). Gestión Jurídica y Forense de la Prueba en el Juicio Oral. Defensoría del Pueblo, Plan Nacional de Capacitación Escuela Nacional de Defensoría Pública "Roberto Camacho Weverberg" (T. III). Bogotá: Stilo Impresores Ltda.

Ley 600 de 2000. Por la cual se expide el Código de Procedimiento Penal. Diario Oficial, No. 44097. Congreso de la República de Colombia, julio del 2000. Recuperado de http://www.secretariasenado.gov.co/senado/basedoc/ ley_0600_2000.html

Ley 906 de 2004. Por la cual se expide el Código de Procedimiento Penal. Diario Oficial No. 45657 y 45658, Congreso de la República de Colombia, agosto de 2004. Recuperado de http://200.75.47.49/senado/basedoc/ley/2004/ ley_09060_204a.html

Ley 1652 de 2013. Por medio de la cual se dictan disposiciones acerca de la entrevista y el testimonio en procesos penales de niños, niñas y adolescentes víctimas de delitos contra la libertad, integridad y formación sexuales. Diario Oficial No. 48849. Congreso de la República de Colombia, julio del 2000. Recuperado de http: / / wsp.presidencia.gov.co / Normativa/Leyes / Documents / 2013 / LEY\%20 1652\%20DEL\%2012\%20DE\%20JULIO\%20DE\%202013.pdf

Lluch, X. (2012). La valoración de la prueba científica. En M. Bustamante. Derecho probatorio contemporáneo. Prueba científica y técnicas forenses (pp. 241-273). Medellín: Universidad de Medellín. 
Martínez, J. (2013). La prueba penal en el acto médico en el sistema acusatorio. Bogotá: Ibáñez.

Michigan, E. D. (1998). Protocolo de entrevista forense (trad. E. Cabañas) Recuperado de http://bscw.rediris.es/bscw/: http://bscw.rediris.es/pub/bscw.cgi/ d368331/Protocolo\%20Entrevista\%20Forense.pdf

Morales, G. (2001). Prueba penal y apreciación técnico científica. Bogotá: Ibáñez.

Morales, G. (2010). ¿Sana crítica o apreciación técnico científica? Análisis de la disyuntiva en el sistema penal acusatorio. Bogotá: Ibáñez.

Myers, J. E. B. (1996). A decade of international reform to accommodate child witnesses: Steps toward a child witness code. En B. L. Bottoms \& G.S. Goodman (Eds.), International perspectives on child abuse and children's testimony: Psychological research and law (pp. 221-265). Thousand Oaks C. A.: Sage.

Muñoz, O. (2006). Sistema penal acusatorio de Estados Unidos. Bogotá: Legis Editores.

National Académy of Sciences. (2011). Reference Manual on Scientific Evidence (3 ed.). Washington, D.C.: The National Academy Press. Recuperado de www.fjc. gov/public/pdf.nsf/lookup/SciMan3D01.pdf/ \$file/SciMan3D01.pdf

Oyuela, R. (2011). Algunos lineamientos conceptuales de las técnicas de recolección de información en el contexto de la psicología jurídica. En G. Hernández, Psicología jurídica Iberoamericana (pp. 297-308). Bogotá: El Manual Moderno (Colombia) Ltda.

Pabón, P. (2006). La prueba pericial. Sistema acusatorio. Bogotá: Librería Jurídica Sánchez R. Ltda.

Parra, J. (2002). La ciencia, la técnica y el proceso penal con miras al nuevo milenio. Revista Nueva Epoca (17), pp. 61-77.

Parra, J. (2011). Manual de Derecho Probatorio. Bogotá: ABC.

Popper, K. (1980). La lógica de la investigación científica, trad. V. Sánchez de Zabala. Madrid: Editorial Tecnos.

Ramírez, F. (2006). Postulados del sistema penal de Estados Unidos y prueba pericial comparada. Derecho penal contemporáneo, (16), 75-96.

Real Academia Española. (2013). Diccionario de la lenguaespañola (22 ed.). Recuperado de www.rae.es: http: / / lema.rae.es / drae / ?va=valor

Reyes, C. \& Said, J. (2009). Intervención Oral en el Sistema Penal Acusatorio II y Gerencia de Procesos Judiciales. En Defensoría del Pueblo. Colección Sistema Penal Acusatorio (T. IV). Bogotá: Alianza Service Ltda. 
Rivera, J. (agosto 11 de 2014). [Comunicación personal]. Copia en poder de Juan José Cantillo Pushaina.

Saade, Y. \& Rojas, A. (2012). Peritaje psicológico: Aspectos relevantes para la evaluación. Recuperado de www.psicologiajuridica.org: http://psicologiajuridica.org./ archives/3286

Sentencia C-396 (2007, mayo 23). M.P. Gerardo Monroy Cabra. Corte Constitucional.

Sentencia 24468 (2006, marzo 30). Casación. M. P. Edgar Lombana Trujillo. Sala de Casación Penal, Corte Suprema de Justicia.

Sentencia 25920 (2007, febrero 21). Casación. M. P. Javier Zapata Ortiz. Sala de Casación Penal, Corte Suprema de Justicia.

Sentencia 26276 (2007, agosto 29). Casación. M. P. Mauro Solarte Portilla. Sala de Casación Penal, Corte Suprema de Justicia.

Sentencia 28862 (2008, febrero 20). Casación. M. P. Sigifredo Espinosa Pérez. Sala de Casación Penal, Corte Suprema de Justicia.

Sentencia 29609 (2008, septiembre 17). Casación. M. P. Julio Enrique Socha Salamanca. Sala de Casación Penal, Corte Suprema de Justicia.

Sentencia 28935 (2009, julio 1). Casación. M. P. José Leonidas Bustos Martínez. Sala de Casación Penal, Corte Suprema de Justicia.

Sentencia 31795 (2009, septiembre 16). Casación. M. P. Yesid Ramírez bastidas y M.P. Julio Enrique Socha Salamanca. Sala de Casación Penal, Corte Suprema de Justicia.

Sentencia 32868 (2010, marzo 10). Casación. M. P. Sigifredo Espinosa Pérez. Sala de Casación Penal, Corte Suprema de Justicia.

Sentencia 32882 (2012, junio 27). Casación. M. P. Javier Zapata Ortiz. Sala de Casación Penal, Corte Suprema de Justicia.

Sentencia 39559 (2013, marzo 6). Casación. M. P. Julio Enrique Socha Salamanca. Sala de Casación Penal, Corte Suprema de Justicia.

Solórzano, C. (2011). La valoración de la prueba pericial psicológica en la jurisprudencia penal colombiana. En G. Hernández. Psicología Jurídica Iberoamericana (pp. 283-296). Bogotá: El Manual Moderno (Colombia) Ltda.

Soria, M. (2005). Manual de psicología jurídica e investigación criminal. En M. Soria. Testimonio en la práctica jurídica (pp. 97-112). Madrid: Pirámide.

Tapias, A. (2008). La psicología forense ante el abuso sexual. En A. Tapias y C. Gutiérrez de Piñeres (Eds.). Psicología jurídica perspectiva latinoamericana (1 ed.) [versión digital]. Bogotá: PSIFORENSE. 
Tapias, A. C., Salas-Menotti, I., Rodríguez, G. \& Solórzano, C. (2009). El valor de la prueba psicológica frente al delito sexual. Recuperado de www.psicologiajuridica. org: http:/ / psicologiajuridica.org/archives/3601

Tapias, A. \& Hernández, G. (2011). Psicología jurídica: una aproximación conceptual. G. Hernández, Psicología Jurídica Iberoamericana (pp. 1-22). Bogotá: Manual Moderno.

Taruffo, M. (2003). Investigación judicial y producción de prueba por las partes. Revista de Derecho Valdivia, 15(0), 205-213. Recuperado de http:/ / www.scielo. cl/scielo.php?pid=S0718-09502003000200010\&script=sci_arttext

Taruffo, M. (2005). Conocimiento científico y estándares de la prueba judicial. Boletín Mexicano de Derecho Comparado (trads. M. Carbonell, y P. Salazar) (pp. 1285-1312). México: Universidad Autónoma de México.

Taruffo, M. (2006). La prueba científica en el proceso civil. En R. Márquez (Ed.), Estudios sobre la prueba (trads. M. Fernández y D. González) (pp. 135-186). México: Universidad Nacional Autónoma de México.

Taruffo, M. (2009). Consideraciones sobre prueba y motivación. En M. de la Iglesia Monje. Consideraciones sobre la prueba judicial (trad. P. Ibáñez) (pp. 17-46). Madrid: Fundación Coloquio Jurídico Europeo Madrid.

Taruffo, M. (2012). El juez imparcial es el juez que persigue la verdad. Revistta Iuris (177), 8-11.

Taruffo, M. (Marzo de 2014) Pruebas Científicas y Reglas de Valoración [Video]. En Insituto Iberamericano de Derecho Procesal. Conversatorio llevado a cabo en el XXIV Jornadas Iberoamericanas de Derecho Procesal, Panamá, Panamá. Recuperado de https: / / www.youtube.com/watch?v=EMQPuqHdv3U

Vázquez, C. (2013). A modo de presentación. En C. Vázquez (Ed.). Estándares de prueba y prueba científica. Ensayos de epistemología jurídica. Madrid: Marcial Pons.

Verbic, F. (2008). La prueba científica en el proceso judicial. Identificación de la noción en el marco de la teoría general de la prueba. Problemas de admisibilidad y atendibilidad. Buenos Aires: Rubinzal - Culzoni.

Zarazo, L. (2010). La sana crítica como sistema de valoración probatoria en materia penal. Bogotá: Ibáñez. 